
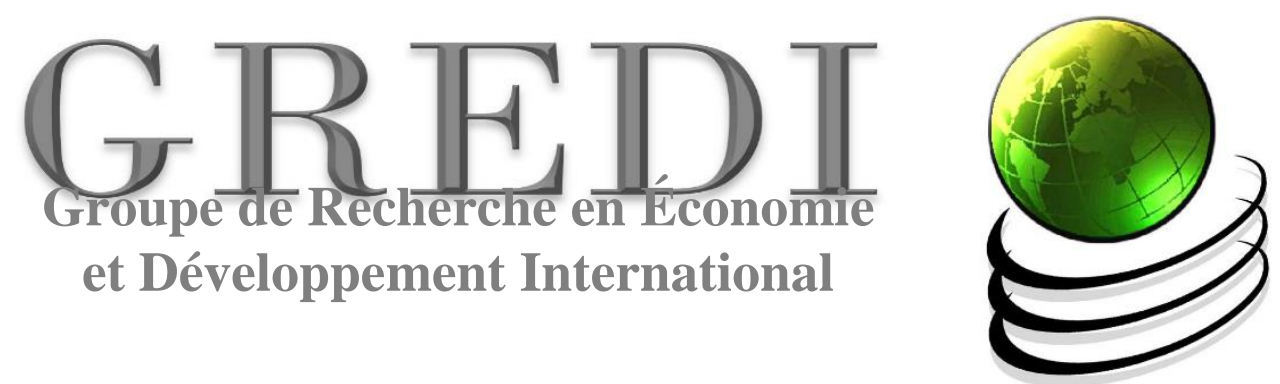

Cahier de recherche / Working Paper

17-07

\title{
Comparative Advantage, Capital Destruction, and Hurricanes
}

\author{
Martino PELLI \\ Jeanne TSCHOPP
}




\title{
Comparative Advantage, Capital Destruction, and Hurricanes *
}

\author{
Martino Pelli ${ }^{\dagger}$ Jeanne Tschopp ${ }^{\ddagger}$
}

July 2017

\begin{abstract}
The comparative advantage of countries evolves over time, yet firms do not continuously adapt their production structure to this evolution. This slow adaptation may be due to high adjustment costs, such as those associated with the disposal of existing physical capital. In practice, these costs may explain why we observe that countries export goods at both ends of the comparative advantage spectrum. This article investigates what happens if the cost of adjusting to the dynamics of comparative advantage is unexpectedly reduced. We use hurricanes to evaluate whether a negative exogenous shock to firms' physical capital leads to a reorganization of exports towards comparative advantage industries. Using a panel of 46 countries and 4-digit industries over the period 1980-2000, we show that the effect of hurricanes on exports is monotonically increasing in comparative advantage. Specifically, export levels drop for industries with a low comparative advantage and grow for industries with a high comparative advantage. Our results also indicate that the process of shifting resources towards higher comparative advantage industries intensifies within the three years following the shock. These findings suggest that if the opportunity cost of adjustment decreases, firms tend to build back better and move up the spectrum of comparative advantage.
\end{abstract}

Keywords: comparative advantage, physical capital, hurricanes.

JEL Classification Codes: F14, O10, Q54

*This paper was previously circulated with the title "The Creative Destruction of Hurricanes". Without implicating them, we would like to thank two anonymous referees, Nina Pavcnik, Marius Brülhart, Olivier Cadot, Jean Imbs, Florian Pelgrin, Aude Pommeret, Katheline Schubert, Eric Strobl, Daniel Sturm, Mathias Thoenig and participants of the EAERE Meeting 2012, the AERE Meeting 2013, the EEA annual congress 2015 and the SEA conference 2015. We also thank seminar participants at the University of Savoie, the University of Lucerne, the Graduate Institute in Geneva, the Chinese Academy of Sciences, Hubei University and UQAM for helpful comments. Jeanne Tschopp is grateful to the Swiss National Science Foundation for its financial support. We are grateful to Dean Yang for sharing his hurricane index.

${ }^{\dagger}$ Department of Economics, University of Sherbrooke, 2500 Blvd de l'Université, Sherbrooke, Q.C., Canada, J1K 2R1; Martino.Pelli@USherbrooke.ca; +1 (819) 821-8000 (ext 61358).

${ }^{\ddagger}$ Department of Economics, Ryerson University, 350 Victoria Street, Toronto, ON, M5B 2K3, Canada; jtschopp@economics.ryerson.ca; +1 (416) 9795000 (ext 3362). 


\section{Introduction}

Comparative advantage is an important determinant of a country's export pattern. According to trade theory, countries should specialize in comparative advantage industries as it will lead to gains from trade and to economic growth. In practice, although export success is highly concentrated in industries with high export capabilities, countries, especially those at lower levels of development, export goods at both ends of the comparative advantage spectrum (e.g. OECD, 2011; Imbs \& Wacziarg, 2003; Cadot et al., 2011, for conclusions along these lines). One possible reason for the absence of specialization is that comparative advantage is not a static phenomenon and that, due to adjustment costs, firms do not adapt their production and export patterns to shifts in comparative advantage. ${ }^{1}$

Due to changing institutions, factor endowments or technology (Blum, 2010), comparative advantage evolves over time (Hanson et al., 2016) and a high comparative advantage industry may gradually move down the ladder of comparative advantage, or vice versa. The steel industry in the United States provides a good illustration of this dynamics as the country progressively lost its comparative advantage after World War II but still accounts for an important fraction of world steel production today. Although aligning export patterns to comparative advantage would be beneficial to the economy, adjustment costs, as such as those associated with the disposing of existing physical capital, investing in new capital, technology, building new network structures or acquiring skills, may prevent firms from switching towards industries or product lines with higher comparative advantage. If continuously adjusting to the dynamics of comparative advantage is too costly, a country may stick to a production and export structure that does not completely align with comparative advantage, therefore, giving rise to production leapfrogging, where adjustments only happen periodically.

The goal of this paper is to evaluate whether a reduction in these adjustment costs leads to a reorganization of exports towards comparative advantage industries. We focus on the capital aspect of the adjustment costs and propose to use hurricanes as a negative shock on existing physical capital. In what follows, the term capital refers to physical capital at the firm level (e.g. machinery, computers, buildings) and not to public capital (e.g. roads, bridges, hospitals), assets or labor inputs.

The rationale for using hurricanes is that they are completely exogenous to economic activity. First, hurricanes are unpredictable: the frequency of occurrence of hurricanes is stationary, hence the incidence of a hurricane does not provide any information on the probability of the next event (Elsner \& Bossak, 2001; Pielke et al., 2008). Moreover, although they tend to occur in coastal areas, hurricanes are erratic phenomena which hit firms and industries randomly. To the extent that hurricanes do not target their victims, they can be considered

\footnotetext{
${ }^{1}$ Following the law of comparative advantage developed by Deardorff (1980), a country exports the goods with the lower autarky relative marginal cost / price. Thus, a country has a comparative advantage in the production of a given good if its autarky price is lower than the one found on the international market.
} 
widespread exogenous phenomena. Finally, as will be argued later on, it does not appear that the possibility of a hurricane strike changes firms' investment or location decisions.

Hurricanes, through their destructive potential, reduce the cost of disposing of existing capital. In that sense, hurricanes reduce the opportunity cost of adjusting to the dynamics of comparative advantage and create an 'opportunity' for reconstruction. In Section 2 we describe a theoretical framework that can help us think about why comparative advantage industries recover while weak comparative advantage industries do not. The mechanism in which we are interested is specific to capital destruction at the firm level and ideally, one would want to work with a panel of firms for a wide range of countries with information on firm-specific location, industrial activity at a fine level of disaggregation, exports and capital stock. Since firm-level data that meet these criteria are hardly available for a cross-country comparison, we work with a panel of 46 countries and 4-digit manufacturing industries over the period 1980-2000, and use hurricanes as a proxy for capital destruction. Our identification strategy consists in regressing the logarithm of industry-country-specific exports towards the US on a country-specific measure of hurricanes, an industry-country-specific term capturing comparative advantage and the interaction of the former two variables. The approach of interacting industry-specific with country-specific variables has been used in the past to explain patterns of trade. ${ }^{2}$ For instance, Rajan \& Zingales (1998) uses such a functional form to examine whether industries that rely more heavily on external financing grow faster in countries with better financial markets, Nunn (2007) tests whether countries with better contract enforcement specialize in contract-intensive industries and Levchenko (2007) asks if countries with better institutions specialize in goods which depend strongly on institutions.

To measure hurricanes, we use an index that reflects their destructive potential in a country in a given year. This index was first proposed by Yang (2008) and possesses the convenient features of being weighted by both wind-speed and population density along the path of hurricanes. ${ }^{3}$ These features are important because they allow to account for the economic activity of the areas a hurricane strikes. One may not expect any effects on exports if a strong hurricane crosses a desert region. At the same time, even if a hurricane strikes an urban area, effects may be negligible if winds are not strong.

This paper does not aim at identifying the sources of comparative advantage and therefore chooses to adopt the traditional Balassa index of revealed comparative advantage. This choice allows us to remain agnostic as to whether comparative advantage stems from Heckscher-Ohlin differences in countries' endowments, Ricardian differences in technology across countries or differences in institutional settings (Costinot, 2009b).

The advantage of an analysis at the industry level, as opposed to one at the firm level, is that data availability enables a cross-country exploration of the dynamics of trade. However,

\footnotetext{
${ }^{2}$ For the theoretical foundation of this approach, see Costinot (2009a,b).

${ }^{3}$ As we argue later on, population density is highly correlated with industrial production.
} 
the limitation of such an aggregated approach is that it makes it more difficult to isolate the effects of a build back mechanism from other channels through which hurricanes could affect exports differentially across industries. For example, the literature on natural disasters documents that in the aftermath of hurricanes, official development assistance, lending from multilateral institutions and migrants' remittances increase while other financial flows such as bank and trade-related lending, foreign direct investments and portfolio investments tend to drop (see e.g. Yang, 2008), likely because the expected rate of returns decrease or because of an increased perception of risk. If the outflow of private investments is more pronounced in comparative disadvantage industries, then a shift towards comparative advantage industries may reflect another type of mechanism whereby firms at the bottom of the distribution are forced to exit due to the lack of financial resources. In addition to this mechanism, we carefully consider a set of alternative channels and show that the main findings do not capture any of these alternatives. These alternative mechanisms are discussed in details in the robustness section and are related, inter alia, to economics growth, changes in the exchange rate, destruction of transport infrastructures and pre-existing trends in exports within industry-country pairs.

Results suggest that in the aftermath of a hurricane, exports are affected differentially across the spectrum of comparative advantage. Most importantly, hurricanes lead to monotone changes in export levels by comparative advantage percentiles, with export levels dropping at the bottom of the distribution and growing at the upper tail of the distribution. Results from a dynamic specification also suggest that the process of shifting resources towards comparative advantage industries occurs within three years and intensifies over this three-years period. Overall, it appears that if the opportunity arises, firms tend to reinvest and move up the ladder of comparative advantage. These results are consistent with the Schumpeterian concept of creative destruction in the sense that hurricanes create an environment of restructuring in which existing technologies of production are weeded out and space for switching towards more productive segments of the economy is created. Finally, results also indicate that the reallocation of resources is driven by drastic changes in industries at both extremes of the comparative advantage distribution. This finding is consistent with a story in which capital destruction produces two types of effects. The first effect occurs across industries as firms in low comparative advantage industries undertake drastic changes and copy the production process of firms in industries whose export success is the highest. The second one happens within comparative advantage industries as firms replace old vintages with newer and more productive capital.

While the key contribution of this paper is to use exogenous variation to identify the presence of a build back better mechanism, the paper also contributes to studies testing for multiple equilibria and to the literatures on the within-country effects of extreme weather events and on the effectiveness of adjustment policies. 
According to economic theory, if a system receives a shock sufficiently strong to send it over a certain threshold, the system may then converge to a different equilibrium. Davis \& Weinstein $(2002,2008)$ use the case of the bombings of Japanese cities during WWII and reach the conclusion that there is no empirical evidence supporting multiple equilibria. Instead, the authors find that Japanese cities suffered directly in the aftermath of the massive bombings but then recovered and returned to their pre-war era equilibrium in terms of population, industry-specific and aggregate production. We observe that in the aftermath of a hurricane, export patterns tend to change permanently in favor of industries with higher comparative advantage. Therefore, contrary to what Davis \& Weinstein $(2002,2008)$ find, our results support multiple equilibria and suggest that the authors' findings may be very specific to the Japanese situation. ${ }^{4}$

This paper also contributes to our knowledge on the within-country effects of extreme weather events, which is particularly important in the current context of climate change and global warming. The frequency and intensity of hydro-meteorological disasters (i.e. hurricanes, flood, wild fires and droughts) has increased dramatically since 1960 (e.g. EM-DAT, World Development Indicators 2009) and so have the costs related to extreme weather events. ${ }^{5}$ For instance, Munich RE reports that the costs associated with extreme weather events has increased from a yearly average of 8.8 billions USD in the 1960 s to 57.5 billions USD in 2005. According to Stern (2007), the cost of hurricanes will reach $0.5 \%$ to $1 \%$ of current world GDP by 2050. The bulk of the rise in damage is due to a surge in natural disasters, of which hurricanes are the most costly (Bevere et al., 2011) and relevant form: $35 \%$ of the global population is affected by hurricanes (Hsiang \& Narita, 2012) and worldwide, hurricanes caused approximately 280 billion dollars of damage over the period 1970-2002 (EM-DAT). A large and growing literature has analyzed the impact of hurricanes on a variety of economic outcomes. ${ }^{6}$ Given their devastating potential, it appears useful to also understand the export dimension of a country's recovery in the aftermath of a hurricane.

Finally, this paper also informs on the effectiveness of adjustment policies. There exist several policies aiming at promoting comparative-advantage-based trade and facilitating the adjustment of an economy to the dynamics of comparative advantage. These policies, which include for instance investing in transportation infrastructures, training, education or promoting capital accumulation and credit access, are generally classified as broad-based and targeted industrial policies. It is often argued that broad-based policies are more effective,

\footnotetext{
${ }^{4}$ In Davis \& Weinstein $(2002,2008)$ the analysis takes place over decades. Unfortunately, our data does not allow us to run such a long run analysis. Yet, when using 10 years worth of lags in the aftermath of a hurricane, we observe a clear divergence in the trend following the disaster. This divergence, instead of re-converging to the pre-hurricane values, stabilizes after roughly three years.

${ }^{5}$ See Emanuel (2005); Elsner (2006, 2007); Hoyos et al. (2006); Webster et al. (2005); Scott et al. (2004).

${ }^{6}$ See for instance Skidmore \& Toya (2002); Belasen \& Polachek (2008); Hsiang (2010); Cuaresma et al. (2008); Miguel \& Roland (2011); Strömberg (2007); Yang (2008); Banerjee et al. (2010); Udry (1994); Maccini \& Yang (2009); Besley \& Burgess (2002); Hsiang et al. (2011); Hsiang \& Jina (2014); Groen \& Polivka (2008).
} 
for the reason that targeted policies, by their very nature, raise the question of which industry to target and involve a political game of thrones, which may work against long-term economic growth and welfare (see e.g. OECD, 2011; Harrison \& Rodríguez-Clare, 2010; Rodrik, 2009). Nevertheless, evaluating these adjustment policies is inherently difficult because they are endogenous to the economic activity, i.e. it is difficult to estimate causal effects of these adjustment policies because not only do these policies affect exports, but also because these policies are implemented precisely in response to particular export patterns. Since hurricanes are widespread exogenous shocks that reduce the opportunity cost of adjusting to the dynamics of comparative advantage, this paper also informs on the effectiveness of broadbased adjustment policies. Our results tend to suggest that undiscriminating policies can be successful at promoting comparative-advantage-based trade.

The remainder of the paper is organized as follows. Section 2 provides a theoretical framework. Section 3 discusses the exogeneity of hurricanes with respect to economic activity. Data are described in Section 4. The paper discusses the identification strategy, the main results, alternative mechanisms and the dynamics of the adjustment in Section 5. The last section concludes.

\section{Theoretical framework}

The framework of our empirical exercise is based on a dynamic model of comparative advantage with putty-clay capital. ${ }^{7}$ In this framework, a country goes through different stages of development, each of them characterized by a different distribution of comparative advantage. For simplicity, the move from one stage to the next happens unexpectedly and for a variety of reasons (e.g. a technological shock or changes in trade policy). Investors take optimal decisions given the information set at their disposal at any point in time, i.e. given the current stage of development and the current distribution of comparative advantage. The dynamics of comparative advantage implies that sectors that were comparative advantage in the past may become comparative disadvantage sectors as a country moves through different stages of development (and vice versa). If investments were putty-putty, capital could move freely across sectors to match the pattern of production that would be consistent with the current law of comparative advantage. However, the putty-clay nature of capital implies that decision-makers are stuck with the choices they made in the past. Consequently, when a country unexpectedly moves to the next stage of development, investors are stuck with their current capital. If this capital still allows investors to cover their average variable costs, they will keep producing with it, as production allows them to cover part of the sunk costs they incurred in the past. Thus, putty-clay capital implies that investments made in the past

\footnotetext{
${ }^{7}$ We thank the referee for providing helpful suggestions on the theoretical framework needed in order to gain a better understanding of our empirical findings.
} 
determine today's pattern of production and explains why countries export goods across the full spectrum of comparative advantage.

In this framework, one would conjecture that if investments were made anew given a country's current stage of development, the pattern of production would not replicate that inherited from the past, as capital would be invested in industries which have a comparative advantage today. To see why this is the case, consider an economy with 2 industries, a textile and a steel industry, and suppose that initially, the country invests capital in the textile industry, in which it has a comparative advantage. Further suppose that as time passes, the country experiences a series of unexpected technological shocks which lead to the complete reversal of comparative advantages. In such a case, the putty-clay nature of capital would explain why the pattern of production and exports does not reproduce the one that would be consistent with the law of comparative advantage. One could conjecture that, since capital is putty-clay and costs are already sunk, the textile industry would keep producing (as long as profits still allow to cover the variable costs), while new investments would be made in the comparative advantage steel industry.

Assume now that a hurricane randomly destroys part of the existing capital in both industries. In this framework, one would expect the destruction of capital to produce two types of effects, one that occurs within industry and another one happening across industries. The first effect is a build back better mechanism that would occur within the comparative advantage industry, here the steel industry, as investors replace old vintages with newer capital. Since newer capital tends to be more productive (either because the destroyed capital was obsolete or because of a higher level of technological development within the country's stage of development), one would expect production to increase in the comparative advantage industry. The second effect is a build back better mechanism which occurs across sectors, as investors whose capital was stuck in the textile industry re-optimize and invest capital in the comparative advantage industry (steel in the example). Therefore, this second effect only happens across sectors, as firms cease operations in the textile industry and reconstruct in the steel industry. To sum up, one would expect exports to shift towards the comparative advantage industry, i.e. one would expect the steel industry to recover and even grow, while the textile industry would not. The main objective of our paper is to test whether the data supports the existence of such a build back better mechanism, i.e. whether, following a shock that destroys physical capital, firms seize the 'opportunity' to invest in industries that align more closely with comparative advantage.

To the best of our knowledge, there is no off-the-shelf theoretical model that can be taken 'as is' to motivate our empirical exercise. There are two theoretical frameworks that are closely related to the story we have in mind. The first one is Redding (1999). This paper introduces the notion of endogenous dynamic comparative advantage and highlights the trade-off that decision-makers face: investing in sectors with a current comparative advantage 
or entering sectors with a weak comparative advantage but high potential for productivity growth. The author argues that under certain circumstances, policies targeted at sectors with low comparative advantage may improve welfare. Redding (1999) is related to Young (1991) which looks at trade and growth in an economy that exhibits bounded learning-by-doing with spillovers across goods. Unlike Redding (1999), the framework proposed by Young (1991) does not explicitly incorporate dynamic comparative advantage. While Redding (1999) proposes a model of dynamic comparative advantage, it only focuses on one factor of production, labor, and lacks the capital aspect we need for our story.

A second theoretical framework that could serve as a basis to motivate our empirical exercise is given in Ishise (2016). Ishise (2016) extends a putty-clay framework with vintage capital à la Gilchrist \& Williams (2005) to a model with two industries and blends it together with a dynamic international trade model in the style of Baxter (1992). In Ishise (2016), capital, which can be thought of as a machine, is characterized by the following attributes: (1) capital is vintage and, because of technological progress, newer machines are more productive than older ones; (2) capital is capacity constraint in the sense that the operational choice is either to allocate a maximum of one worker to a machine or to keep the machine idle; (3) investments are irreversible; and (4) there are idiosyncratic productivity differences across machines of the same vintage. Ishise (2016) describes a sorting situation in which the most productive machines produce goods that are exported, machines with moderate productivity level produce goods that are used for the domestic market and machines with productivity levels at the bottom of the productivity distribution do not operate. In addition, the author finds that an industry with a larger productivity variation in machines has a higher productivity, a lower industrial price and, as a result, a higher comparative advantage. One missing aspect needed for our story is the idea of a country moving through different stages of development. However, Ishise (2016) could produce a story consistent with our empirical findings if one is willing to relate technology to the distribution of productivities of machines and assume that a technological shock shifts comparative advantage by changing this distribution.

\section{The exogeneity of hurricanes to economic activity}

Can hurricane strikes really be considered exogenous to economic activity? The question lies at the heart of our identification strategy and deserves to be backed up by some evidence.

We begin with two important considerations. First, it has been shown that the frequency of occurrence of hurricanes is stationary, which means that the occurrence of a hurricane does not provide any information on the probability of observing a similar event in the same location in the future (Elsner \& Bossak, 2001; Pielke et al., 2008). Second, hurricanes are erratic phenomena. Although hurricanes generally hit coastal areas and forecasting techniques are constantly improving, it is still very difficult to predict their exact path. Therefore, even 
though governments engage in ex-ante disaster risk reduction activities, it does not appear that the possibility of a hurricane strike changes firms' investment or location decisions.

Evidence suggests that individuals have internalized this erratic behavior. For instance, Lindell et al. (2007) show that the perceived probability of being affected by a hurricane does not increase significantly even after being hit by a hurricane. Along similar lines, Wu \& Lindell (2014) use an experimental setting and show that decision makers tend to wait until it is too late in order to evacuate areas at risk of being hit. Dessaint \& Matray (2014) analyse firms' behaviour and find that managers tend to react to hurricanes in their vicinity by increasing cash holdings for a short period of time only. Observing these types of drastic, yet temporary, changes in behavior in the aftermath of a hurricane suggests that managers do not internalize the disaster risk into their decision making process. These observations are important in relation to the mechanism investigated in this paper. If investment decisions were affected by the probability of being struck by a hurricane, then observing a shift towards comparative advantage industries could reflect a mechanism different from the one we seek to uncover, whereby, for instance, firms await the catastrophy to invest in new physical capital. In such a case, the expectation of a catastrophy would compromise the optimal path of investments and lead to misallocation of resources.

Consistent with the aforementioned findings, anecdotal evidence does not suggest that hurricane-prone areas are deserted or occupied by a cluster of specific industries. For instance, in India, a high concentration of firms is found in hurricane-prone areas. Figure A.1 in the Appendix shows hurricanes' best tracks in India for the period 1970-2000. ${ }^{8}$ The figure indicates that the majority of hurricanes' activity takes place in the north-east, north-west and southern tip of the country. Figure A.2 in the Appendix shows a high concentration of firms in hurricane-prone areas, i.e. in the metropolitan area of Kolkata, the plains leading to New Delhi in the north east of the country, the highly industrialized Gujarat in the north west, and the equally highly industrialized southern parts of Kerala and Tamil Nadu in the south.

Another example are the Philippines, where the majority of manufacturing activities is located on the northern island which tends to be more prone to hurricanes than the southern island. Figure A.3 in the Appendix shows hurricanes' best tracks in the northwestern Pacific Ocean over the period 1980-2005. The red box indicates that the southern part of the Philippines is rarely hit by hurricanes, if at all. Figure A.4 in the Appendix presents the gross value added in the manufacturing sector for 2012. The figure shows that the majority of the manufacturing activities are located around Manila, despite a particularly high disaster risk in the area. Instead, low gross value added in manufacturing is observed in the relatively safer southern island. According to the Department of Trade and Industry of the

\footnotetext{
${ }^{8} \mathrm{~A}$ hurricane best track reports the position, the strength of the wind and the diameter characterizing the eye of a hurricane at intervals of six hours.
} 
Philippines, in 2014, roughly $33 \%$ of the Philippines' GDP was generated in Manila, of which $12.5 \%$ came from manufacturing. The industries found in and around Manila are chemicals, textiles, clothing, electronic goods, food, beverages, and tobacco products. ${ }^{9}$ One could argue that the southern part of the country is mountainous and therefore less suitable to industrial activities, yet this is not the case. If individuals' location decisions were affected by hurricanes, one would expect the Philippines' economic activity to be clustered in the safer South instead. Moreover, although we cannot be sure without knowing the industrial composition of firms across regions, given the variety of industries found in the area of Manila, it seems also plausible to suppose that firms in comparative advantage industries do not systematically self-select outside of risky areas. This is important to our identification strategy; if firms in comparative advantage industries did systematically self-select into hurricane-safe areas, then observing a reorganization of exports towards comparative advantage industries would simply reflect a mechanical reallocation of resources from risky to safer areas and not necessarily a build-back better mechanism.

\section{Data}

\subsection{Hurricanes}

The term hurricane typically describes severe tropical storms over the Atlantic or the East Pacific Ocean (i.e. storms with a wind speed exceeding 74 miles/119 kilometers per hour). ${ }^{10}$ The same event in the Western Pacific is known as a typhoon - or tropical cyclone - over the Indian Ocean and in Oceania. Hurricanes always originate in tropical areas, but can end up in temperate areas, i.e. the US Atlantic coast or the temperate coast of East Asia and Japan.

We measure hurricanes using an index constructed in Yang (2008). The raw data used to build the index come from two US government agencies: the NOAA Tropical Prediction Center (for Atlantic and Eastern North Pacific hurricanes) and the Naval Pacific Meteorology and Oceanography Center/Joint Typhoon Warning Center (for hurricanes in the Indian Ocean, Western North Pacific, and Oceania). These centers provide best tracks for each hurricane. Figure 1 shows all best tracks over the period 1985-2005 and Figure 2 focuses on the best

\footnotetext{
${ }^{9}$ http://www.dti.gov.ph/rog/index.php/metro-manila

${ }^{10}$ The formation of a hurricane requires a set of particular conditions. First, to a depth of 50 meters, the ocean needs to reach at least $79.7^{\circ} \mathrm{F}\left(26.5^{\circ} \mathrm{C}\right)$. At this temperature, water creates instability in the overlying atmosphere. Second, the water vapor needs to cool rapidly while rising in the atmosphere. This condensation releases the heat which powers the hurricane. Third, high humidity is required: disturbances in the troposphere form more easily if it contains a lot of moisture. Fourth, the storm's circulation should not be disrupted by high amounts of wind shear. Wind shear refers to the variation of wind over either horizontal or vertical distances. Finally, the Coriolis effect should be strong enough to deflect winds blowing toward the low-pressure center and to create a circulation, i.e. the distance from the equator needs to be greater than $555 \mathrm{~km}-$ or 5 degrees of latitude. The Coriolis effect is caused by the rotation of the earth and the inertia of the mass experiencing the effect.
} 
tracks for Oceania in 2010.

Figure 1: Best tracks, over the period 1985-2005.

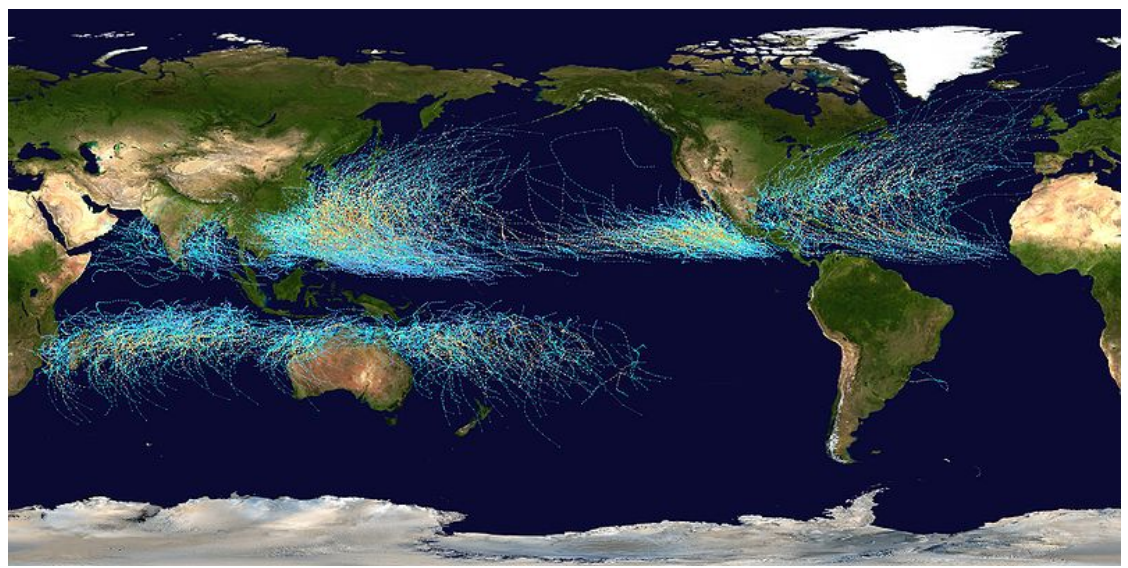

Source: National Hurricane Center (NOAA).

Figure 2: Best tracks, Oceania, 2010.

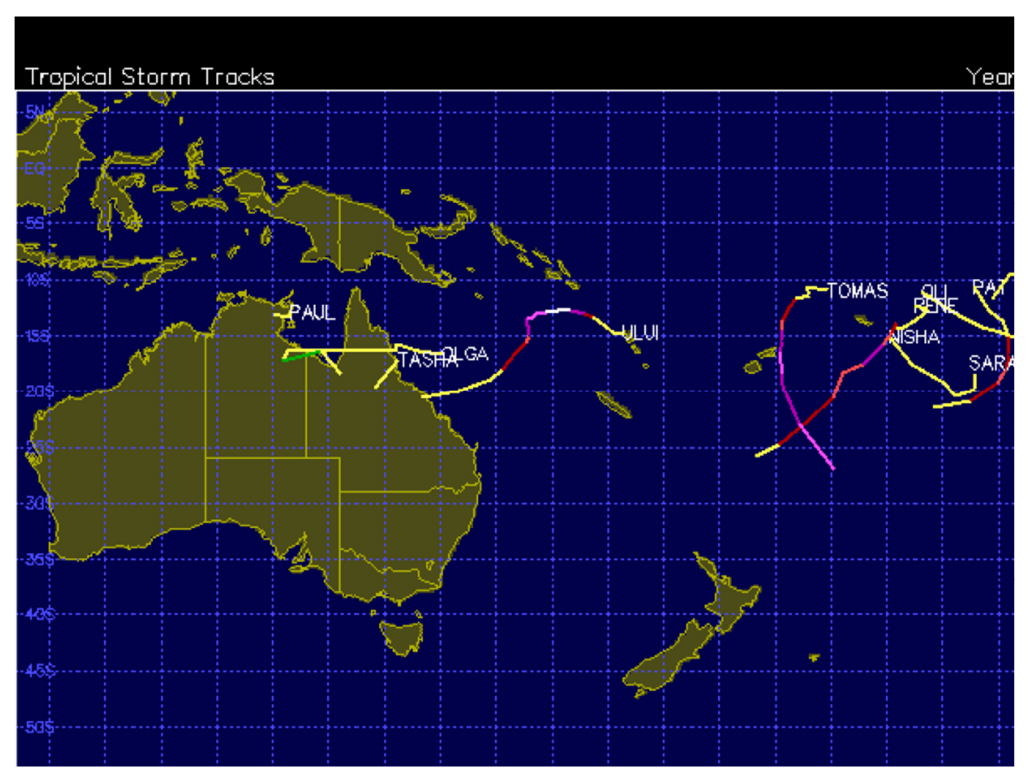

Source: Naval Pacific Meteorology and Oceanography Center.

The index proposed by Yang (2008) is a country-year-specific measure that reflects the destructive potential of hurricanes in a country in a given year, taking into account both their force and the population density along their path. This measure, denoted $H_{c t}$, is defined as

$$
H_{c t}=\sum_{l} \sum_{s} x_{l s c t} / L_{c t}
$$


where $c, t, l$ and $s$ are country, time, individual and hurricane subscripts, respectively, and where $L$ denotes population. $x_{l s c t}$ captures individual $l$ 's affectedness by hurricane $s$ in country $c$ at time $t$ and is given by

$$
x_{l s c t}=\left(w_{l s c t}-33\right)^{2} /\left(w^{M A X}-33\right)^{2},
$$

where $w_{l s c t}$ and $w^{M A X}$ are hurricane- $s$ wind speed and the maximum wind speed observed in the sample, respectively. The number 33 represents the hurricane wind speed threshold (in knots); i.e. the threshold above which a storm becomes a hurricane. The wind speeds above this threshold (as captured by $\left(w_{l s c t}-33\right)$ and $\left.\left(w^{M A X}-33\right)\right)$ are squared in order to capture the force exerted by the wind on built structures. Therefore, individual affectedness $x_{l s c t}$ varies between 0 (when a storm just makes it to the hurricane level) and 1 (for the strongest hurricane in our sample). ${ }^{11}$ Individuals within a 0.25 -degree-square worldwide grid are treated homogeneously with respect to wind exposure. Taking this information into account, the storm index $H_{c t}$ can theoretically vary between 0 and the total number of hurricanes within a year. Consider for instance the case of Nicaragua which experienced only one hurricane, Cesar, in 1996. For that country and particular year, the maximum value the hurricane index could possibly take is one. For this maximum to be reached, Cesar should be the strongest hurricane ever observed in the entire sample and have affected all individuals in Nicaragua in 1996 in the exact same way. In general, a value of 1 is highly unlikely as a hurricane rarely hits the entire surface (and thus, population) of a country and even if it would, since wind speeds change as the hurricane progresses, it is still highly improbable that all individuals would be affected similarly.

Hurricanes inflict damages in three different ways: through the force exerted by wind, surges and precipitation. The index focuses on wind speed and, therefore, is well suited to the study of the effect of hurricanes on economic activity. The focus on wind speed renders the hurricane measure exogenous to economic activity. Indeed, whereas floodings may be caused by excessive deforestation, wind destruction does not depend on land usage. The identification of the desired effect requires locating regions whose manufacturing activity is touched. Worldwide data on the location of industrial production does not exist at the same resolution level as for population. Yet, industrial production is usually located in the vicinity of urban areas, making population density a good proxy for industrial production. ${ }^{12}$ Indeed, a storm with extremely high winds passing through a scarcely populated area is unlikely to affect the manufacturing industry. At the same time, a hurricane crossing a densely populated

\footnotetext{
${ }^{11}$ Equation (2) may give the impression that the index treats symmetrically a storm characterized by winds at, for instance, 34 knots and one with winds at 32 knots. This is not the case as tropical storms are classified as hurricanes only if their wind speed reaches 33 knots. Therefore, the database does not contain any data point with winds speeds lower than 33 knots.

${ }^{12}$ For instance, in 2010 in the Philippines, the correlation between population density and industrial GDP (at the regional level) equals to $86.5 \%$.
} 
area will be weighted more heavily in the index even if characterized by a low wind speed. Finally, expressing the index in per capita terms is convenient because it allows us to account for the size of the country. Consider a large country like China and a small one like Belize, and a strong hurricane crossing only one of the 0.25-degree-square grids. The hurricane will likely have a smaller impact on the Chinese economy then on the one of Belize. Normalizing the index by population size makes the impact of hurricanes on aggregate economic activity comparable across countries.

Table 1 shows summary statistics for the hurricane index, $H_{c t}$, by country over the period 1980-2000. Countries are ranked in ascending order according to their mean value for $H_{c t}$. The overall mean and the maximum values are 0.019 and 0.282 , respectively. China, Mexico, Vietnam and the Philippines experienced hurricanes every year of the sample. The statistics suggest that, on average, the destructive potential of hurricanes in the Philippines (average of 0.04) is 40 times higher than that in Mexico (average of 0.001), 20 times higher than that in China (average of 0.002) and 7 times higher than that in Vietnam (average of 0.006). Countries like Barbados and Trinidad and Tobago highlight the advantage of using a continuous variable over a count one to measure hurricanes. For example, both countries experienced hurricanes in two out of the twenty years included in the sample. A count variable would treat both countries identically, although the index indicates that the destructive potential of hurricanes was on average 47 times larger in Trinidad and Tobago than it is in Barbados. Figure 3 provides a visual characterization of the hurricane measure $H_{c t}$. The boxplot shows the interquartile variation, median, range and outliers of the destructive potential of hurricanes for each country in our sample. Countries are ranked in ascending order according to their mean value for $H_{c t}$. The figure stresses a large amount of variation in the hurricane measure across countries.

Our sample includes both islands and continental countries, as well as countries with substantial size differences and at various stages of development. According to the 1990 World Bank classification of income, the sample contains 12 low, 15 low-middle, 10 uppermiddle and 9 high income countries. Although it includes a variety of countries, it is worth noting that our sample is limited along several dimensions. First, the number of countries included in the sample is dictated by export data availability. These data do not exist for all countries experiencing hurricanes. Second, some countries located in a hurricane-prone area did not experience any hurricane over the period under consideration. Third, not all countries in the world are in hurricane-prone areas; some countries will never experience a hurricane. One might be concerned that this last point could introduce a selection bias in our estimations, especially if the people living in the countries contained in our sample are prepared for hurricanes. Even if this possibility exists, we do not think that our results are affected by a selection bias, since, as explained in Section 3, individuals and firms do not seem to internalize the risk posed by hurricanes. In addition, the sample includes countries such 
Figure 3: Boxplot hurricanes

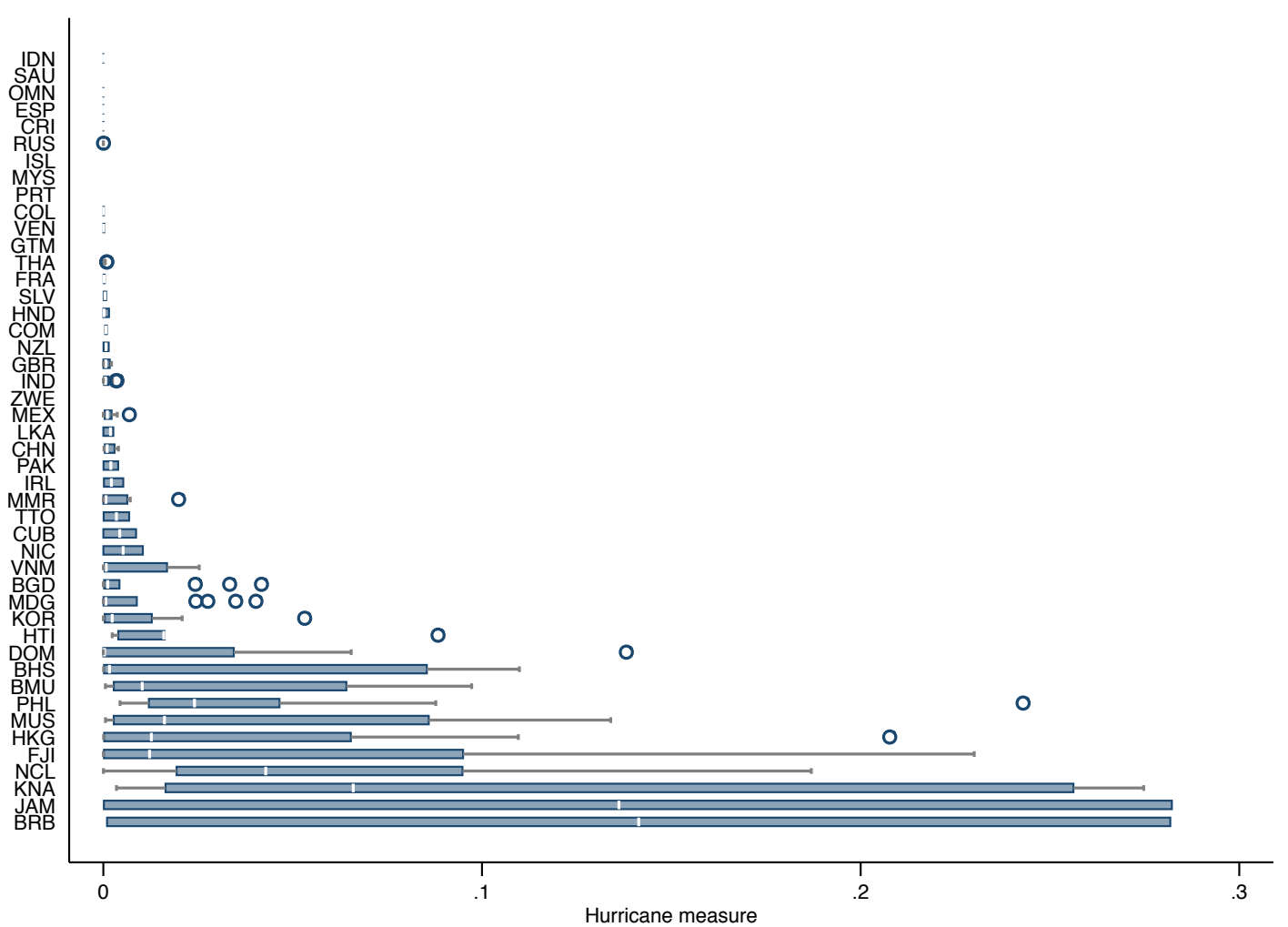

Note: Countries with no boxplot are countries with less than three relatively small hurricanes over the period 1980-2000. Isocodes can be found in Table B.1 of the Appendix. 
Table 1: Summary statistics for hurricanes, 1980-2000

\begin{tabular}{|c|c|c|c|c|c|c|}
\hline Country & Mean & Std. Dev. & Min. & Max. & $\begin{array}{c}\text { Nb. of years } \\
\text { with hurricanes }\end{array}$ & $\begin{array}{c}\text { Country size } \\
\left(\text { in } \mathbf{k m}^{2}\right)\end{array}$ \\
\hline All 46 countries & 0.019 & 0.047 & 0.000 & 0.282 & & \\
\hline Indonesia & 0.000 & 0.000 & 0.000 & 0.000 & 2 & $1,919,440$ \\
\hline Saudi Arabia & 0.000 & - & 0.000 & 0.000 & 1 & $2,149,690$ \\
\hline Spain & 0.000 & 0.000 & 0.000 & 0.000 & 2 & 505,370 \\
\hline Russia & 0.000 & 0.000 & 0.000 & 0.000 & 10 & $17,075,400$ \\
\hline Costa Rica & 0.000 & 0.000 & 0.000 & 0.000 & 2 & 51,100 \\
\hline Oman & 0.000 & 0.000 & 0.000 & 0.000 & 4 & 212,460 \\
\hline Iceland & 0.000 & - & 0.000 & 0.000 & 1 & 103,001 \\
\hline Malaysia & 0.000 & - & 0.000 & 0.000 & 1 & 330,803 \\
\hline Portugal & 0.000 & - & 0.000 & 0.000 & 1 & 92,090 \\
\hline Colombia & 0.000 & 0.000 & 0.000 & 0.000 & 3 & $1,141,748$ \\
\hline Venezuela & 0.000 & 0.000 & 0.000 & 0.000 & 3 & 916,445 \\
\hline Guatemala & 0.000 & - & 0.000 & 0.000 & 1 & 108,890 \\
\hline Thailand & 0.000 & 0.000 & 0.000 & 0.001 & 12 & 513,120 \\
\hline France & 0.000 & 0.000 & 0.000 & 0.000 & 2 & 674,843 \\
\hline El Salvador & 0.000 & 0.000 & 0.000 & 0.001 & 2 & 21,040 \\
\hline Honduras & 0.001 & 0.001 & 0.000 & 0.001 & 3 & 112,492 \\
\hline Comoros & 0.001 & 0.000 & 0.000 & 0.001 & 2 & 2,170 \\
\hline New Zealand & 0.001 & 0.001 & 0.000 & 0.001 & 3 & 268,021 \\
\hline United Kingdom & 0.001 & 0.001 & 0.000 & 0.002 & 4 & 243,610 \\
\hline India & 0.001 & 0.001 & 0.000 & 0.004 & 20 & $3,287,263$ \\
\hline Zimbabwe & 0.001 & - & 0.001 & 0.001 & 1 & 390,757 \\
\hline Mexico & 0.001 & 0.002 & 0.000 & 0.007 & 21 & $1,972,550$ \\
\hline Sri Lanka & 0.002 & 0.001 & 0.000 & 0.003 & 3 & 65,610 \\
\hline China & 0.002 & 0.001 & 0.000 & 0.004 & 21 & $9,640,821$ \\
\hline Pakistan & 0.002 & 0.003 & 0.000 & 0.004 & 2 & 796,095 \\
\hline Ireland & 0.003 & 0.003 & 0.000 & 0.005 & 3 & 84,421 \\
\hline Myanmar & 0.003 & 0.006 & 0.000 & 0.020 & 13 & 676,578 \\
\hline Trinidad and Tobago & 0.003 & 0.005 & 0.000 & 0.007 & 2 & 5,128 \\
\hline Vietnam & 0.006 & 0.006 & 0.000 & 0.025 & 21 & 331,698 \\
\hline Bangladesh & 0.008 & 0.014 & 0.000 & 0.042 & 15 & 147,570 \\
\hline Madagascar & 0.008 & 0.013 & 0.000 & 0.040 & 19 & 587,040 \\
\hline Republic of Korea & 0.009 & 0.014 & 0.000 & 0.053 & 16 & 100,210 \\
\hline Cuba & 0.010 & 0.020 & 0.000 & 0.067 & 11 & 109,886 \\
\hline Nicaragua & 0.010 & 0.015 & 0.000 & 0.031 & 4 & 130,373 \\
\hline Haiti & 0.025 & 0.036 & 0.002 & 0.088 & 5 & 27,750 \\
\hline Dominican Republic & 0.026 & 0.051 & 0.000 & 0.138 & 8 & 48,730 \\
\hline Bahamas & 0.029 & 0.046 & 0.000 & 0.110 & 10 & 13,939 \\
\hline Bermuda & 0.032 & 0.042 & 0.001 & 0.097 & 8 & 53.3 \\
\hline Philippines & 0.040 & 0.052 & 0.004 & 0.243 & 21 & 299,764 \\
\hline Mauritius & 0.041 & 0.051 & 0.001 & 0.134 & 11 & 2,040 \\
\hline Hong Kong & 0.046 & 0.071 & 0.000 & 0.208 & 9 & 80.4 \\
\hline Fiji & 0.060 & 0.082 & 0.000 & 0.230 & 11 & 18,274 \\
\hline New Caledonia & 0.061 & 0.055 & 0.000 & 0.187 & 11 & 18,575 \\
\hline Saint Kitts and Nevis & 0.114 & 0.120 & 0.003 & 0.275 & 6 & 261 \\
\hline Jamaica & 0.139 & 0.141 & 0.000 & 0.282 & 3 & 10,991 \\
\hline Barbados & 0.141 & 0.199 & 0.001 & 0.282 & 2 & 430 \\
\hline
\end{tabular}

Note: There are 46 countries for which we have data on exports and hurricanes. The column Min. represents the minimum value of a hurricane in a given country. Values of 0.000 denote values smaller than 0.001 .

as Guatemala, Malaysia and Zimbabwe, which experienced only one weak hurricane over the 20 years of the study period. One would think that countries hit by sporadic episodes are largely unprepared. 


\subsection{Exports and comparative advantage}

Export data are taken from the NBER United Nations bilateral trade data. The data cover a large set of countries for the period 1962 to 2000 and contains trade data, disaggregated at the 4-digit level. ${ }^{13}$ The analysis of this paper covers the years 1980-2000 and focuses on manufacturing exports from 46 countries. ${ }^{14}$ The analysis is restricted to the manufacturing sector because the mechanism of interest directly relates to physical capital destruction. Finally this paper only uses industries with positive export values over the entire period. ${ }^{15}$ Given that hurricanes only tend to hit specific areas in a country, it is unlikely that they would lead to the disappearance of an entire industry. Including in the sample only industries caracterized by positive export flows over the entire period also partly deals with the high volatility which characterizes export data. Industries with low export values are usually characterized by a high frequency of entry/exit and often related to reporting errors. Another advantage of our sample is the absence of zero trade flows which are usually difficult to deal with.

Table B.2 of the Appendix shows summary statistics for the manufacturing sector, both in terms of the share of manufacturing exports in total exports and of manufacturing production in GDP, by country, over the period 1980-2000. The share of manufacturing exports varies from a minimum of $0.7 \%$ for Nicaragua to a maximum value of $98.4 \%$ for Bermuda. Even though the variability seems high, on average manufacturing exports represent the $49 \%$ of total export values. This number is larger than the value representing the share of the manufacturing sector in GDP, which averages to $17 \%$.

Comparative advantage This paper uses the traditional Balassa index of revealed comparative advantage. This measure is given by the proportion of country c's exports in industry $i$ normalized by the proportion of world exports in that particular industry. That is,

$$
\text { Balassa }_{i c t}=\left(X_{i c t} / \sum_{i} X_{i c t}\right) /\left(X_{i t} / \sum_{i} X_{i t}\right),
$$

where $X_{i c t}$ denotes exports of industry $i$ in country $c$ towards the world at time $t$ and $X_{i t}$ is aggregate exports of industry $i$ at time $t$. A value of the index larger than 1 indicates that country $c$ has a comparative advantage in industry $i$. Instead, if its value is between 0 and 1 , the country has a comparative disadvantage in that industry. In what follows, the paper uses

\footnotetext{
${ }^{13}$ We decided to use trade data disaggregated at the 4-digit level instead of the 6-digit level since good quality data at the 6-digit level are available only starting in 1995.

${ }^{14}$ The sample is limited to countries which experienced at least one hurricane over the period under consideration and for which the hurricane index is available.

${ }^{15}$ Note that taking a longer time period would imply losing a significant number of observations, possibly because of changes in technology and consumption habits.
} 
the logarithm of the Balassa index to measure comparative advantage, that is:

$$
\mathrm{CA}_{i c t}=\log \text { Balassa }_{i c t},
$$

where $C A_{i c t}$ denotes comparative advantage. Figure A.5 of the Appendix shows the distribution of the Balassa measure, expressed in logs, by year, across countries and industries. The figure shows that, taken across countries and industries, the distribution of comparative advantage moves slowly over the years and tends to become more concentrated as one moves towards the year 2000. Columns (1) through (4) of Table B.3 in the Appendix show summary statistics of the Balassa measure for every country this paper covers, over the period 1980-2000. The table shows considerable variation in comparative advantage across countries.

The main advantage of using the Balassa measure is that it is based on a broad definition of comparative advantage, therefore allowing us to be agnostic about the sources of comparative advantage. One limitation of this measure, however, is that it is affected by country-specific geographical characteristics, demand-side attributes or policies that may distort trade. Therefore, the Balassa index may reflect part of these confounding factors in addition to any underlying comparative advantage.

Dependent variable The dependent variable is given by the log of industry-countryspecific exports towards the U.S. Focusing on one single destination country has the advantage of removing destination-specific demand-side confounds. Another reason for this restriction is that, since it is constructed using country-industry exports, the Balassa measure of comparative advantage might be endogenous. Using exports towards one single destination market, as opposed to all trading partners, alleviates potential reverse causality. Table B.4 in the Appendix reports the summary statistics for country-specific exports towards the US as a share of country-specific aggregate exports.

\section{$5 \quad$ Empirical Strategy}

\section{$5.1 \quad$ Identification}

The main specification regresses the logarithm of industry-country exports towards the US on the index of hurricanes, the logarithm of the Balassa measure of revealed comparative advantage, the interaction of the two variables and an entire set of country, industry and year dummies, as well as industry and country trends:

$$
\log X_{i c t, U S}=\alpha H_{c t}+\beta C A_{i c(t-1)}+\gamma\left(H_{c t} \times C A_{i c(t-1)}\right)+d_{c}+d_{i}+d_{t}+\tau_{i}+\tau_{c}+\varepsilon_{i c t},
$$

where $X_{i c t, U S}$ denotes exports of country $c$ in industry $i$ towards the US at time $t . d_{c}, d_{i}$ 
and $d_{t}$ denote country, industry and time dummies, respectively. $\tau_{i t}$ and $\tau_{c t}$ are industry and country trends, respectively. $\varepsilon_{i c t}$ is the error term.

Since the paper only focuses on industries for which exports are strictly positive over the entire period, the sample does not contain zero trade flows. Note that the lagged value of comparative advantage is used in the regression. This choice ensures that measured comparative advantage is not affected by current hurricanes or by the dependent variable (although focusing on one single destination market should already filter out reverse causality concerns).

The coefficient $\alpha$ captures the marginal effect of hurricanes on the dependent variable for industries whose measured comparative advantage (expressed in logs) is zero. Thus, a negative coefficient would imply that hurricanes cause a decrease in export values for industries whose $C A_{i c t}=0$. The coefficient $\beta$ captures the importance of comparative advantage on export flows. Since $C A_{i c t}$ is increasing in comparative advantage, $\beta$ is expected to be positive if countries tend to specialize in the production and export of industries for which they have a comparative advantage. Whether hurricanes affect industries differentially depends on $\gamma$, the coefficient on the interaction term. The way hurricanes shape export patterns, however, is given by the marginal effect of hurricanes on exports for each level of comparative advantage. The marginal effect depends on both coefficients $\alpha$ and $\gamma$, and is computed as follows:

$$
\alpha+\gamma C A_{i c(t-1)}
$$

If resources shift from comparative disadvantage to comparative advantage industries, one would expect the marginal effects of hurricanes on exports to be monotonically increasing with comparative advantage, which can only occur if $\alpha<0$ and $\gamma>0$. For example, $\alpha>0$ and $\gamma<0$ would generate a monotonically decreasing function and imply a movement of exports down the scale of comparative advantage. Two positive coefficients would imply the marginal effect to be U-shaped, and vice versa.

\subsection{Baseline results}

Table 2 presents the baseline results. All columns include industry, country and year dummies in addition to industry and country trends. Standard errors are clustered at the country level. The first and second columns only include the measure of hurricanes and comparative advantage, respectively. Both variables are introduced jointly in column (3). Column (4) corresponds to a specification that includes the interaction of both variables.

Unlike the estimates obtained on the hurricane index, the coefficients on the measure of comparative advantage are positive, statistically significant and remarkably stable across specifications. When the Balassa index is excluded, the coefficient on the hurricane measure is positive, yet statistically insignificant. The coefficient becomes negative when the variable capturing comparative advantage is added and, finally, negative and statistically significant 
Table 2: Baseline results

\begin{tabular}{|c|c|c|c|c|}
\hline \multirow{2}{*}{ Dependent variable } & \multicolumn{4}{|c|}{$\log$ exports $_{i c t, U S}$} \\
\hline & (1) & $(2)$ & (3) & (4) \\
\hline Hurricane $_{c t}$ & $\begin{array}{c}0.062 \\
(0.45)\end{array}$ & & $\begin{array}{c}-0.19 \\
(0.42)\end{array}$ & $\begin{array}{l}-3.59^{* * *} \\
(1.00)\end{array}$ \\
\hline Balassa $_{i c(t-1)}$ & & $\begin{array}{l}0.89^{* * *} \\
(0.016)\end{array}$ & $\begin{array}{l}0.89^{* * *} \\
(0.016)\end{array}$ & $\begin{array}{l}0.89^{* * *} \\
(0.016)\end{array}$ \\
\hline Balassa $_{i c(t-1)}{ }^{*}$ Hurricane $_{c t}$ & & & & $\begin{array}{l}0.89^{* * *} \\
(0.22)\end{array}$ \\
\hline $\begin{array}{l}\text { Industry, country and year dummies; } \\
\text { Industry and country trends }\end{array}$ & yes & yes & yes & yes \\
\hline Observations & 68325 & 68325 & 68325 & 68325 \\
\hline$R^{2}$ & 0.54 & 0.78 & 0.78 & 0.78 \\
\hline
\end{tabular}

at the $1 \%$ level when the interaction term is included. This result suggests that the estimate in column (3) may mask heterogeneous effects across industries. The coefficient on the interaction term is positive and statistically significant at the $1 \%$ level, indicating that industries are indeed affected differentially by hurricanes. ${ }^{16}$

Interpreting the magnitude of $\alpha$ or $\gamma$ alone makes little sense as the marginal effect ought to be computed using the estimates of both coefficients. The signs of the estimates obtained in column (4) suggest, however, that the marginal effects of hurricanes on exports are monotonically increasing with comparative advantage. Therefore, it appears that exports tend to shift towards comparative advantage industries in the aftermath of a hurricane. However, at this stage it remains unclear whether export levels increase or decrease over the entire spectrum of comparative advantage, or whether they drop at the bottom of the distribution of comparative advantage and grow as one moves towards the upper tail of the distribution.

\footnotetext{
${ }^{16}$ Table A.1 of the Online Appendix verifies whether the baseline results are driven by extreme values. The table shows the results obtained when values of the Balassa measure below the 10th percentile and above the 90th percentile are dropped from the sample. The coefficient on the interaction term is robust to these changes both in terms of sign and statistical significance. If at all, the magnitude of the estimate increases after we cut off the tails of the distribution. Table A.2 of the Online Appendix, shows the results obtained when current values of the comparative advantage measure are used instead of lagged values. The results are basically unchanged. Thus, this table shows two things. First, comparative advantage changes slowly, and second hurricanes do not seem to affect comparative advantage. Table A.3 of the Online Appendix replaces each value of comparative advantage by its percentile value corresponding to its rank in the distribution of comparative advantage. The goal of this exercise is to verify whether the baseline estimates are the mechanical result of the fact that the comparative advantage measure takes negative and positive values. Table A.3 of the Online Appendix suggests that this is not case. Finally, in Section C in the Online Appendix, we test the robustness of the main results to an alternative measure of comparative advantage, recently developed by Hanson et al. (2016).
} 
To obtain a more complete picture on how exports are affected in each industry, the paper uses equation (5) to compute the marginal effect at each level of comparative advantage. The results are presented in Figure 4. The gray histogram in the background shows the distribution of comparative advantage across countries, industries and years. The black line corresponds to the marginal effect of hurricanes on export levels for each level of comparative advantage and the green dashed lines correspond to the $95 \%$ confidence interval. Export values of industries located at the bottom $43.32 \%$ and the top $23.54 \%$ of the distribution are affected in a statistically significant manner. The figure shows that the marginal effects are monotonically increasing, with export levels dropping at bottom $43.32 \%$ and growing at the top $23.54 \%$ of the distribution. This evidence is suggestive of a build back better mechanism leading to a reorganization of production and exports from comparative disadvantage towards industries with relatively higher comparative advantage. These results are consistent with the idea of creative destruction as it appears that if the opportunity araises, firms in comparative disadvantage industries do not stick to their current production structure but instead tend to reinvest and move up the ladder of comparative advantage.

The right-hand side vertical axis shows that the magnitude of the marginal effects can be large, especially at the extremes of the comparative advantage distribution. Although the magnitude of these effects appears to be large, one needs to bear in mind that the measure of hurricanes is relatively small, with a maximum value of $0.282 .{ }^{17}$

To get a better idea of the average total effects over the spectrum of comparative advantage, Figure 5 plots smoothed predicted changes in exports, by quantile of comparative advantage. The figure is obtained by carrying out a locally weighted regression of the predicted total effects on comparative advantage and suggests that on average, exports tend to respond negatively up to the 60th quantile and thereafter, positively. The shape of the curve also shows that industries at both extremes of the distribution respond more abruptly than those in the middle of the distribution. This finding is consistent with a story in which, when capital is destroyed and firms are given the opportunity for reconstruction, firms at the very bottom of the distribution undertake drastic changes and invest in modes of production that are considerably more productive or, at least, invest in those industries whose export success is the largest. The increase in exports at the top of the distribution is also compatible with a story in which firms in comparative advantage industries replace old capital with newer and more productive capital, although taken alone, this within-industry effect would fall short of explaining the drop in exports that is observed at the bottom of the distribution.

\footnotetext{
${ }^{17}$ Figure A.6 in the Appendix shows the predicted total effects on exports for each level of comparative advantage. These effects are computed using each of the values of the hurricane index in the sample. In contrast with Figure 4, the right axis exhibits much smaller numbers in magnitude, which is to be expected given the range of values that the hurricane index can take. Each series of dots in the figure represents a hurricane-country-year triplet. Flatter curves represent weaker hurricanes, while steeper curves represent larger ones. For instance, in Figure B.1 of the Online Appendix, the red curve represents the predicted total
} 
Figure 4: Marginal effects

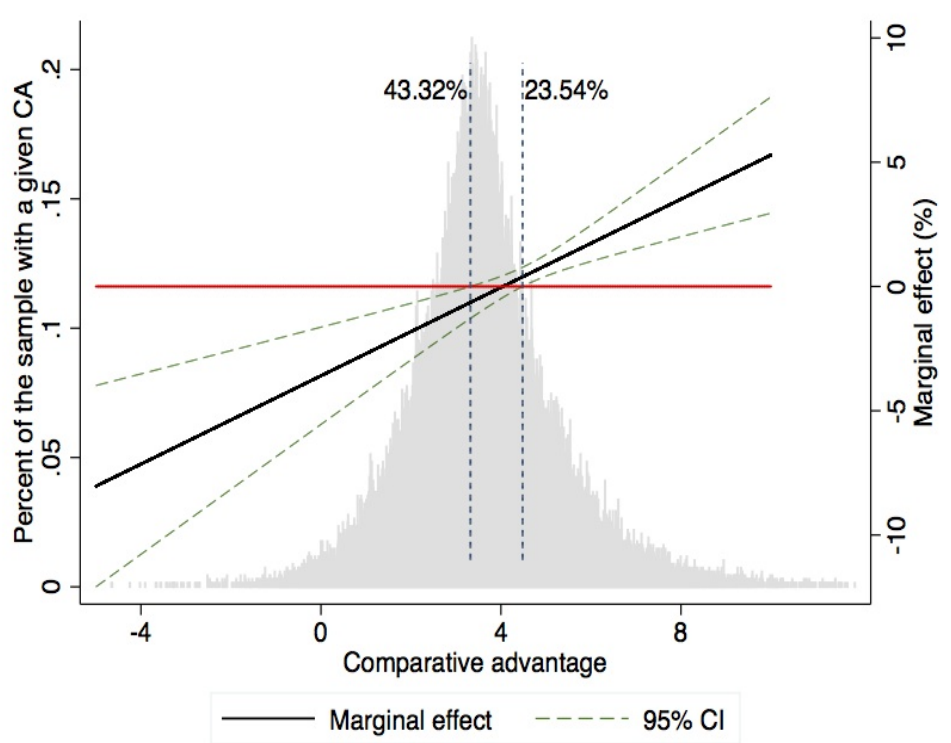

Notes: The black line is given by $\alpha+\gamma \cdot C A_{\text {cit }} \forall C A_{\text {cit }} \in[-5,12]$. The range is generated at intervals of 0.01 and reflects the range of comparative advantage observed in the data.

Figure 5: Smoothed total effects

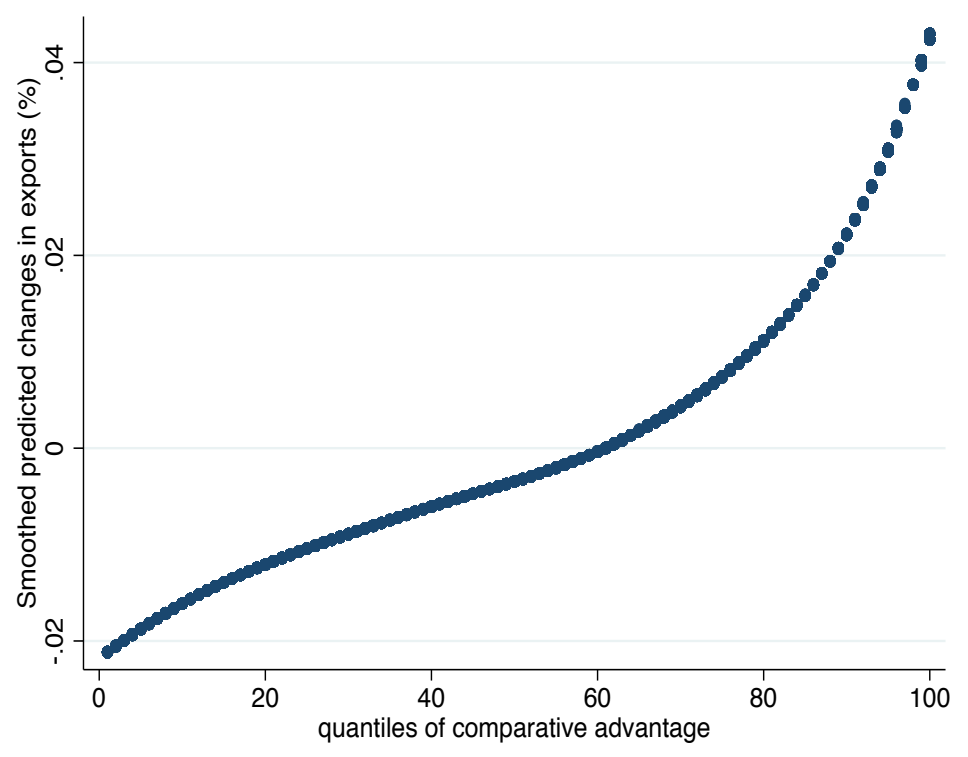


If the physical capital channel is operational, one would expect the effect of interest to depend on industry-specific capital intensity and to be the greatest in those industries where the potential for destruction is the largest. We test for the physical capital channel in Section D of the Online Appendix. We find that, as expected, capital-intensive industries tend to suffer more from hurricanes. At the bottom of the comparative advantage distribution, industries that rely heavily on physical capital show a statistically significant drop in exports while marginal effects are statistically insignificant for industries with low values of physical capital. As it is the case for the baseline estimates, the marginal effects are monotonically increasing in comparative advantage irrespective of the level of physical capital. As one moves towards higher levels of comparative advantage, the marginal effects become statistically insignificant for capital-intensive industries. Thus, it appears that for comparative advantage industries which heavily rely on physical capital, the decrease in exports experienced on impact is mitigated due to the build-back better mechanism described above. For comparative advantage industries with low physical capital intensity, effects are positive and statistically significant. This suggests that these industries, which are initially sheltered from hurricanes, subsequently benefit from a reconstruction effect in which firms in comparative disadvantage industries reinvest in industries with a higher comparative advantage. Therefore, our results suggest that the drop in exports observed in Figure 4 is driven by comparative disadvantage industries with high-capital intensity. Results also indicate that comparative advantage industries with low capital intensity drive the positive shifts in exports observed at the top of the distribution of comparative advantage. Overall, these findings provide evidence that the physical capital channel is operational.

effects of hurricanes on exports for Hong Kong in 1995. 


\subsection{Robustness}

The first part of this section investigates a series of alternative mechanisms which may potentially interfere with the baseline estimates. The second part of this section compares the baseline estimates to those obtained when restricting the sample to a subset of countries, namely islands and then countries with isolated episodes.

\subsubsection{Alternative mechanisms}

We start by investigating whether our estimates merely reflect differences in industry-specific capital specificity. Assume that in our sample, industries with a lower comparative advantage are systematically more intensive in physical capital while comparative advantage industries use relatively less capital. In such a case, since hurricanes destroy capital, industries with a comparative disadvantage would be affected disproportionately more, not because of a build back better mechanism but because industries differ in their capital intensity; i.e. because those industries that are more prone to capital destruction specifically have a comparative disadvantage. To test whether our estimates capture differences in the capital specificity of industries, we add industry-year dummies (at the 4-digit level) to the baseline specification. ${ }^{18}$ The inclusion of these dummies also allows us to control for all other time-varying industry characteristics that may interfere with our estimates, such as industry-specific dependence on transport infrastructures, external finance, natural resources or human capital. As shown in column 2 of Table 3 (the first column shows the baseline estimates), accounting for differences in industry-specific capital specificity does not alter our baseline findings.

We then examine whether the baseline estimates capture an already existing trend of exports at the industry-country level. The reason why this may be the case is that, by construction, the traditional Balassa measure of comparative advantage reflects the export success of an industry in a country. If export success tends to correlate with the trend of exports of each industry in each country, then the baseline estimates may be capturing an existing trend effect rather than a reallocation of exports towards the top of the distribution of comparative advantage. In such a case, the baseline estimates would indicate that hurricanes simply accelerate the decline or the growth of an already declining or growing industry, rather than inciting firms to build back better. The paper tests this possibility in Table 3. To perform a stringent test, we sequentially add industry-year dummies, industry-country fixed effects and industry-country trends to the baseline specification. The last column shows estimates of the most demanding specification. ${ }^{19}$ Although the magnitude of the estimates somewhat decrease as one includes extra sets of dummies, the qualitative aspect of the results

\footnotetext{
${ }^{18}$ To include such a large number of fixed effects in the regression we use the stata package reghdfe developed by Correia (2017).

${ }^{19}$ The number of observations decreases as one moves across column because singleton observations are dropped from the estimation.
} 
remains unaltered, suggesting that our baseline estimates are not the result of an industrycountry-specific trend. This finding is quite remarkable considering the high level of industrial disaggregation (4-digits) (and therefore the large amount of controls) used in each of these specifications. 
Table 3: Controlling for industry-year, industry-country, country-year dummies and industry-country trends

\begin{tabular}{|c|c|c|c|c|}
\hline & $(1)$ & $(2)$ & $(3)$ & $(4)$ \\
\hline Hurricane $_{c t}$ & $\begin{array}{c}-3.59^{* * *} \\
(1.00)\end{array}$ & $\begin{array}{c}-3.63^{* * *} \\
(1.19)\end{array}$ & $\begin{array}{c}-2.04^{* * *} \\
(0.65)\end{array}$ & $\begin{array}{c}-1.33^{* *} \\
(0.61)\end{array}$ \\
\hline Balassa $_{i c(t-1)}$ & $\begin{array}{c}0.89^{* * *} \\
(0.016)\end{array}$ & $\begin{array}{c}0.90^{* * *} \\
(0.017)\end{array}$ & $\begin{array}{c}0.56^{* * *} \\
(0.030)\end{array}$ & $\begin{array}{c}0.37^{* * *} \\
(0.034)\end{array}$ \\
\hline Balassa $_{i c(t-1)} *$ Hurricane $_{c t}$ & $\begin{array}{c}0.89^{* * *} \\
(0.22)\end{array}$ & $\begin{array}{c}0.91^{* * *} \\
(0.27)\end{array}$ & $\begin{array}{c}0.53^{* * *} \\
(0.12)\end{array}$ & $\begin{array}{c}0.34^{* * *} \\
(0.092)\end{array}$ \\
\hline Industry, country and year dummies & Yes & Yes & Yes & Yes \\
\hline Industry-country dummies & No & No & Yes & Yes \\
\hline Industry trends & Yes & No & No & No \\
\hline Country trends & Yes & Yes & Yes & Yes \\
\hline Industry-country trends & No & No & No & Yes \\
\hline Industry-year dummies & No & Yes & Yes & Yes \\
\hline Observations & 68325 & 67471 & 67351 & 67351 \\
\hline$R^{2}$ & 0.78 & 0.81 & 0.91 & 0.94 \\
\hline
\end{tabular}

In what follows, the paper includes additional variables to the main specification to test whether the baseline estimates capture alternative mechanisms through which hurricanes may affect exports differentially. Our goal is to rule out industry-country-specific channels that are potentially correlated with comparative advantage. Including additional controls to the baseline specification tends to result in a decrease in the number of observations, which may render the comparison of the new coefficients to the baseline estimates difficult. For this reason, before presenting any new specification, the paper first presents the estimates obtained when running the baseline specification on the sample of observations that is left when introducing each of these additional controls.

The first alternative channel this paper considers is related to economic growth. A recent literature on natural disaster (see e.g. Hsiang \& Jina, 2014) shows that hurricanes can affect economic growth. Another strand of the literature argues that the patterns of trade are correlated to the economic development of a country. For example, OECD (2011) shows that countries at lower levels of development tend to export goods produced at all ends of the comparative advantage distribution while richer economies tend to concentrate production in industries with a clear comparative advantage. If hurricanes have a positive impact on economic growth, at least in the long run, then our results may just reflect a shift towards higher stages of economic development. To test for this alternative channel, the paper controls for GDP and GDP per capita, each of them interacted with the Balassa index. ${ }^{20}$ Nevertheless, note that since there is no clear consensus in the natural disaster literature on how hurricanes affect economic growth, it is not entirely clear whether and how omitting these two variables

\footnotetext{
${ }^{20}$ Data on GDP and GDP per capita are taken from the World Development Indicators.
} 
would bias the baseline results. Results are reported in columns (2) and (3) of Table 4. Adding these two controls does not alter the qualitative aspect of the baseline results. Although the coefficients on both the hurricane index and the interaction term slightly decrease in magnitude, the sign and statistical significance of the estimates is preserved.

The second alternative mechanism relates to changes in the exchange rate. It is possible that a country experiences a currency devaluation in the aftermath of a hurricane. If the devaluation benefits comparative advantage industries disproportionately more, then the baseline estimate may capture the effect of the currency devaluation instead of a build-back mechanism. This possibility is examined in column (5) of Table 4 by controlling for the real effective exchange rate (REER) interacted with the Balassa index. ${ }^{21}$ Although the coefficients on the REER and the interaction term are statistically significant and have the expected sign, controlling for the REER does not alter the estimates of interest, suggesting that the baseline estimates do not capture the effect of variations in the exchange rate.

Another issue concerns the short term macroeconomic consequences of hurricanes associated with a decline in the current account. Following a negative shock on capital, it is possible that the production of a country slows down while, thanks to foreign borrowing/domestic absorption, destroyed capital is rebuilt. Since, by definition of the Balassa index, a comparative disadvantage industry exports relatively less, one would expect the proportional decline in exports to be mechanically larger in those industries. This effect would be even more evident if in our sample, the destruction of capital were systematically greater in industries with a lower Balassa index. Such a scenario, however, would be a current account problem playing through existing patterns of trade rather than a build back better story, which may or may not occur in the longer run. We evaluate this current account issue in column (7) of Table 4 and add a country's external balance as well as its interaction with the Balassa index to the baseline specification. ${ }^{22}$ Neither the coefficient on the external balance variable nor that on the interaction term is statistically significant, and more importantly, the coefficients of interest remain unaltered, suggesting that omitting changes in the current account does not create a significant bias.

Hurricanes can damage installation and production platforms of natural resources and cause price spikes in the short term. While year dummies control for price changes, our baseline results may pick up the effect of fluctuations in natural resources reserves, especially if industries situated at the bottom of the comparative advantage distribution depend on natural resources to a larger extent. If instead hurricanes do not destroy extractive-linked

\footnotetext{
${ }^{21}$ Exchange rate data are from the IMF. The real effective exchange rate is the ratio of the nominal effective exchange rate (NEER) to a price deflator. The NEER is expressed on the base $2005=100$ and measures the value of a currency against a weighted average of several foreign currencies. An increase in the REER indicates that exports become more costly and imports cheaper.

${ }^{22}$ We use external balance data (on goods and services, as a percentage of GDP) as for our sample, current account data were not available before 2004. Data are taken from the World Bank Indicators.
} 
infrastructures, one would expect industries that are more dependent on natural resources to be more likely to preserve comparative advantage. We account for this potential channel in column (9) of Table 4 which also include a measure of natural resources rents (and as before, interact this control variable with the Balassa index). ${ }^{23}$ Results show that adding this extra control does not affect the estimates of interest.

Another channel this paper examines relates to financial flows. The literature on the impact of natural disasters on financial flows documents an increase in official development assistance, lending from multilateral institutions and migrants' remittances in the aftermath of a hurricane (see e.g. Yang, 2008). However, evidence suggests that private financial flows, such as bank and trade-related lending, foreign direct investments and portfolio investments, tend to decrease, possibly because of a decrease in the expected rate of returns or an increase in the perception of risk. Omitting financial flows from the main specification may bias the baseline estimates if the inflow of foreign aid targets comparative advantage industries specifically, or if private investments are prone to leave comparative disadvantage industries to a larger extent. In such a case, the baseline results could reflect the fact that at the bottom of the distribution of comparative advantage, firms tend to exit for good for the reason that they simply do not have the resources to reinvest. Alternatively, the baseline results could capture a flow of new entries or an expansion of firms at the top of the distribution. Table 5 investigates this channel and sequentially includes official development assistance, lending from multilateral institutions, migrants' remittances, bank and trade-related lending, foreign direct investments and portfolio investments in the baseline specification. ${ }^{24}$ As in Table 4, we also interact each of these variables with the Balassa index. The estimates on each of these controls is statistically insignificant and more importantly does not alter the baseline estimates. Therefore, it does not appear that omitting any of these financial flows from the baseline specification creates a significant bias.

The last mechanism we examine relates to the destruction of transport infrastructure. Besides destroying capital and production structures of firms, hurricanes can severely damage transportation systems. By causing delays, partial closures and diversions of air, water and land transportation, hurricanes can inflate trade costs, at least temporarily. Models of heterogenous firms and trade show that, by reducing firms' exporting profitability, an increase in trade costs causes the least productive firms to exit the export market (e.g. Melitz, 2003). If, as shown by Bernard et al. (2007), this effect is magnified for comparative disadvantage industries, the baseline estimates may reflect part of the temporary negative effect of increased transport costs rather than build-back better forces. This paper evaluates this possibility using the following proxies of infrastructure capital (each of them interacted with

\footnotetext{
${ }^{23}$ Data on resource rents are taken from the World Bank Indicators and are defined by the sum of oil rents, natural gas rents, coal rents (hard and soft), mineral rents, and forest rents, as a percentage of GDP.

${ }^{24}$ Each of the controls is taken from the World Development Indicators and expressed in 2000 US\$.
} 
our measure of comparative advantage): million tons per kilometer transported by railways and by air freight, investments in transport with private participation, and capital formation in the public sector. ${ }^{25}$ Results are shown in Table 6 . In general, controlling for infrastructure capital does not alter the qualitative aspect of the results; the estimates of interest preserve their sign and statistical significance. Interestingly, the inclusion of the railway variable causes the coefficient on the hurricane index to grow from -2.69 to -6.95 , indicating that the baseline estimate may be biased upward. This result suggests a negative correlation between rail transport and hurricanes that could reflect the fact that countries with better-developed rail systems suffer less from hurricanes. In fact, greater availability of alternative routes likely enables firms to divert the delivery of goods and limits the delays caused by the catastrophe. ${ }^{26}$ Column (3) also suggests that the coefficient on the hurricane index may suffer from a bias, although a smaller one in magnitude, likely because a smaller share of manufacturing goods is airfreighted. Nevertheless, although Table 6 suggests that the baseline estimates may be slightly biased, controlling for transport infrastructures only reinforces the main result and corroborates the build-back better mechanism this paper seeks to identify.

In Tables 7, 8 and 9, we adopt a stricter approach to control for these industry-countryspecific channels that may be correlated with comparative advantage and propose to interact each of the extra country-specific controls with industry dummies. Take for instance the channel associated with financial flows and imagine that, by decreasing private financial flows, hurricanes cause industries whose external finance dependence is the highest to suffer disporportionately more. In that case, our baseline estimates may be biased if industries with a comparative disadvantage also have relatively larger proportions of external financing and, therefore, one would want to augment the baseline specification with a term that interacts financial flows with a measure of industry-specific external finance dependence. Similarly for the mechanism related to transport infrastructures, our estimates may pick up an effect associated with differences in industry-specific transport dependence if transport dependence (negatively) correlates with comparative advantage. Measures of industry-specific characteristics used in the literature, such as external finance dependence, human or physical capital intensity, are constant over time and generally vary in their degree of industrial disaggregation (e.g. see Rajan \& Zingales, 1998; Braun, 2003; Raddatz, 2006; Manova, 2008). As for measures of industry-specific transport dependence, they can be constructed using the direct requirement table from the transportation satellite accounts (TSA) of the Bureau of transportation statistics. The Bureau provides four releases for the TSA (1996, 1997, 2002-2006 and 2002-2012) but only the 1997-release matches our time frame so that transport depen-

\footnotetext{
${ }^{25}$ Each of these variables is taken from the World Development Indicators. Note that the million tons per kilometer transported by rail captures country-specific track density. This measure is adjusted to the size of the country through the country fixed effects. Capital formation in the public sector includes all kinds of public infrastructures, as for example schools or hospitals.

${ }^{26}$ Interacting the railway variable with the hurricane index leads to similar results.
} 
dence would be constant over time as well. Given the time-invariant component of these industry-specific measures, we use industry dummies directly. Results of this more general and demanding approach suggest that our baseline estimates are not capturing any of these industry-country-specific alternative channels that may correlate with the Balassa index. ${ }^{27}$

\footnotetext{
${ }^{27}$ Interacting industry-year dummies with each of the country-specific controls yields similar results.
} 


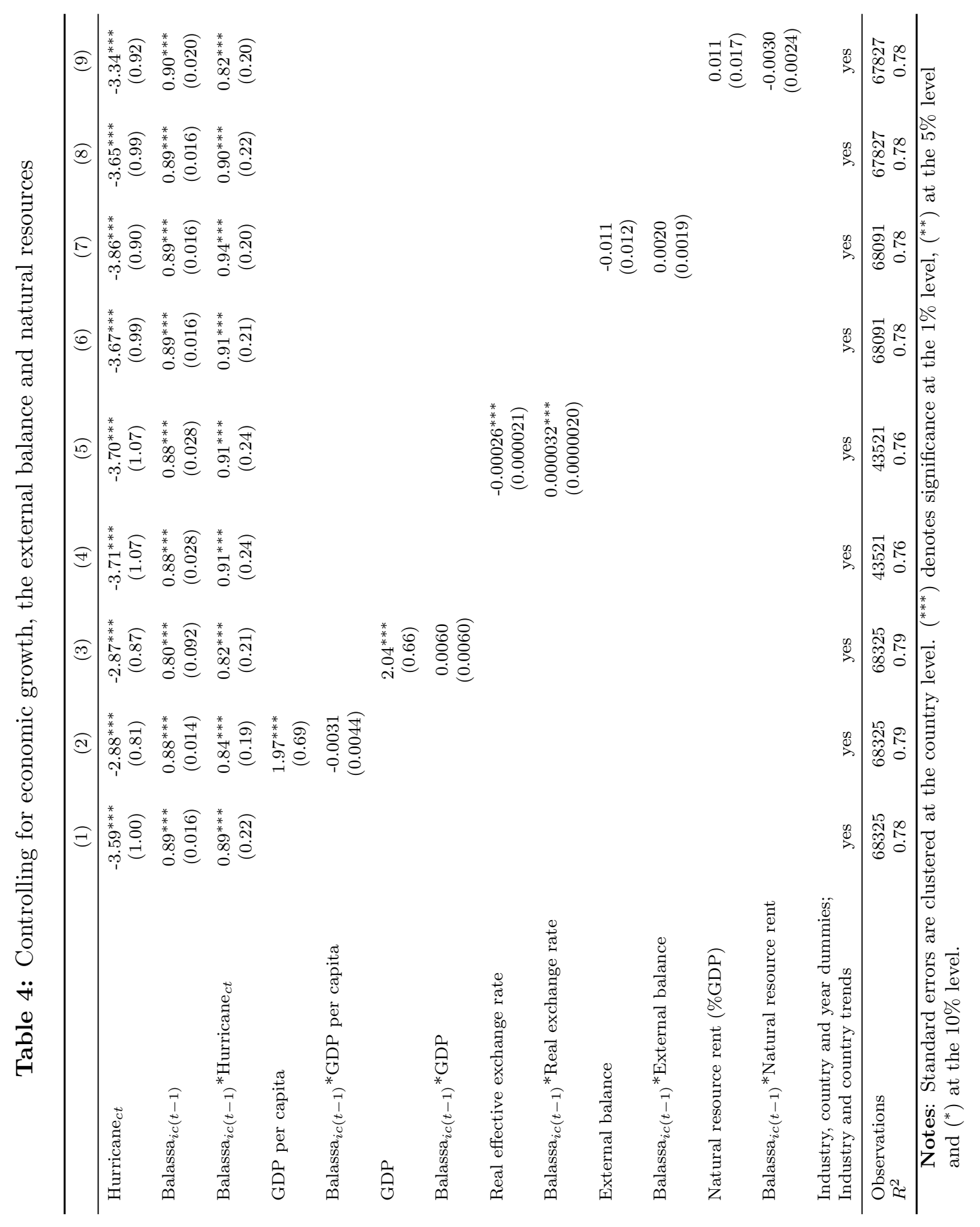




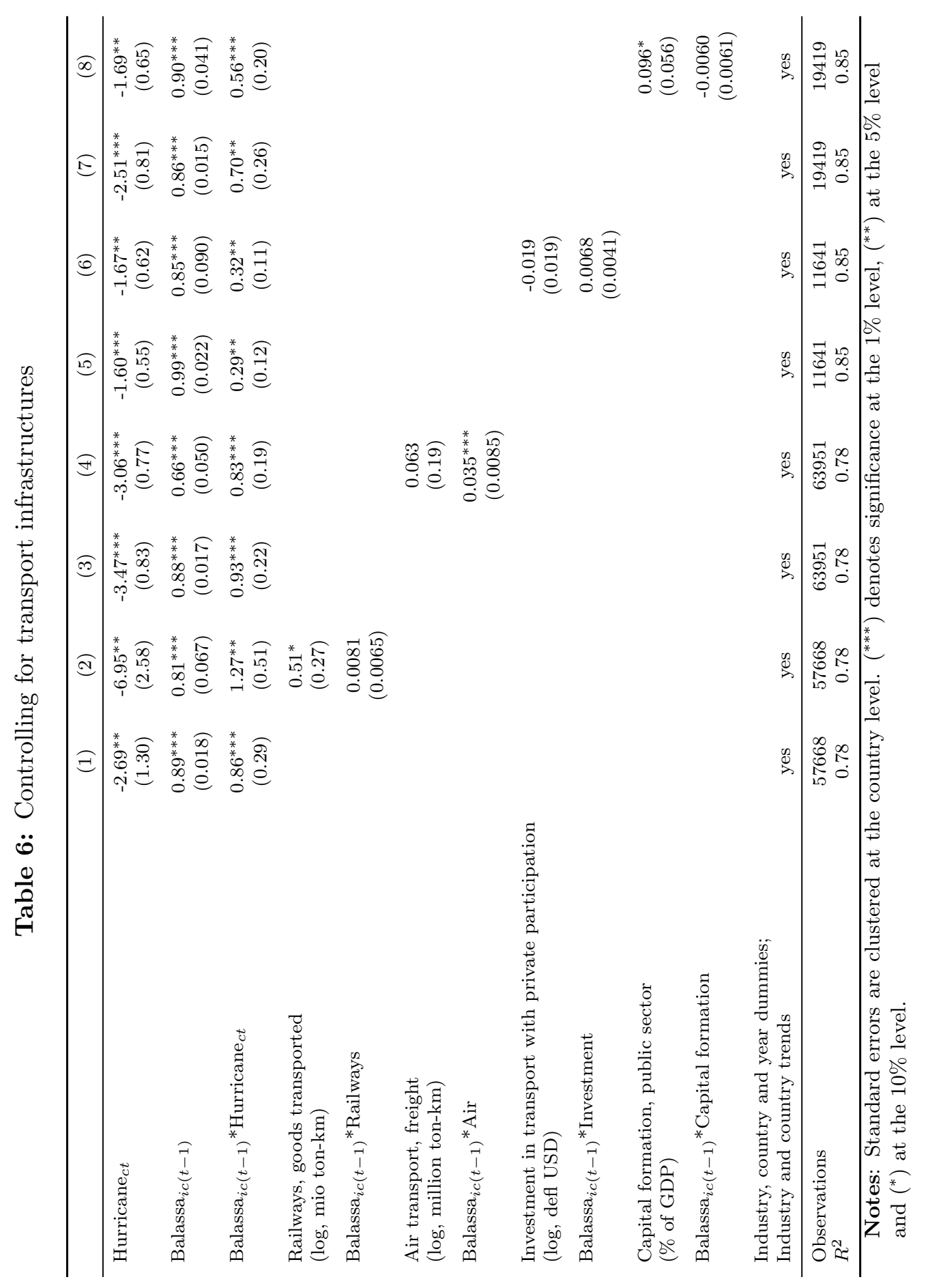




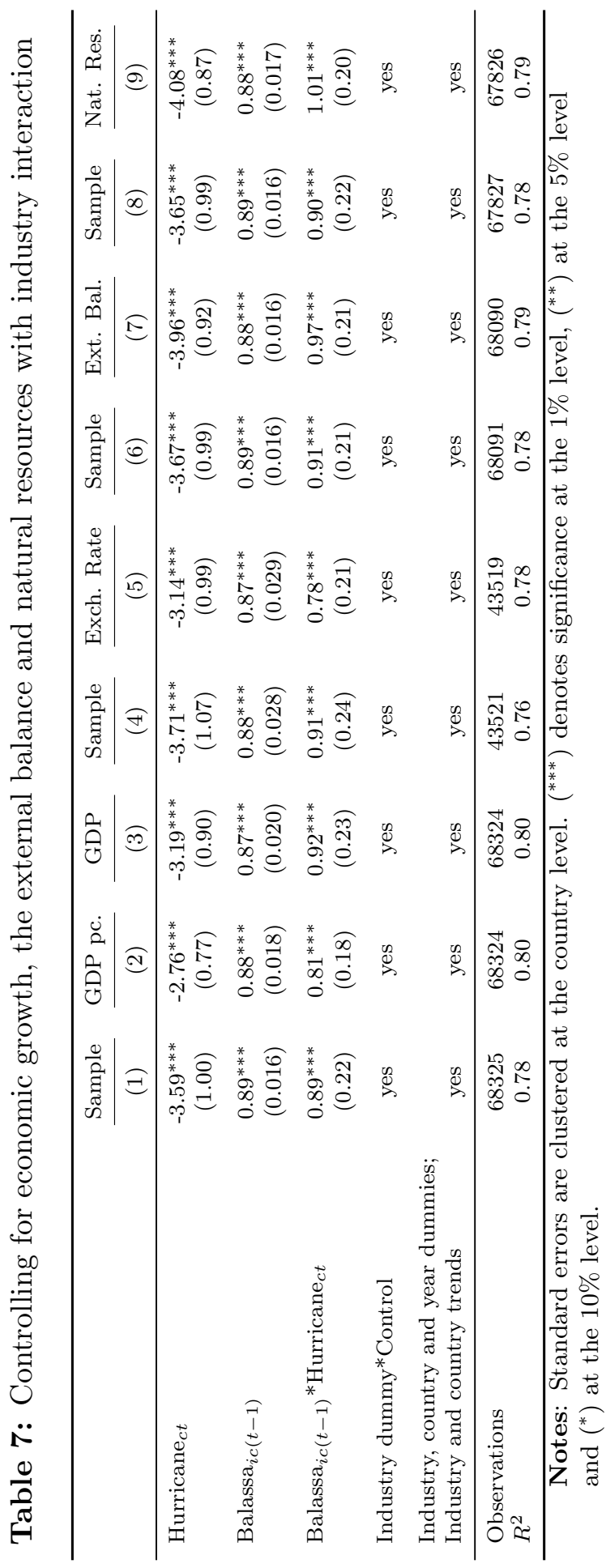




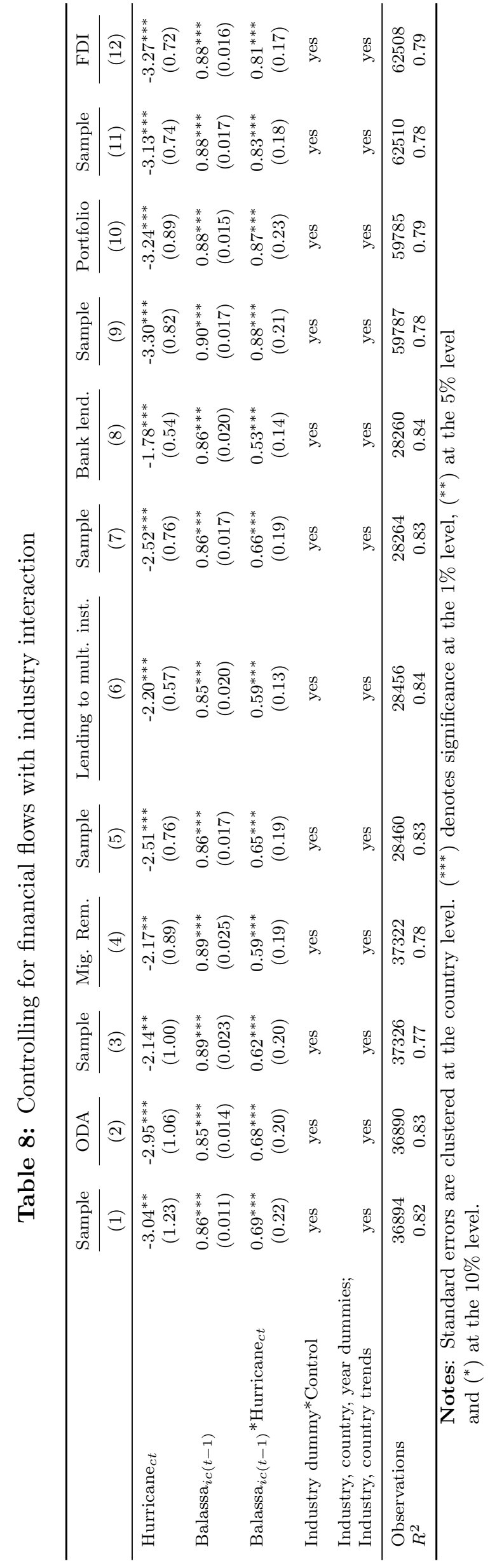




\subsubsection{Islands and isolated episodes}

This paper uses data aggregated at the industry-country level. For this reason, one would expect the baseline results to be driven by countries for which hurricanes are not limited to coastal areas but instead hit regions that represent a larger fraction of aggregate exports. Regional data on exports disaggregated at a the industry level are hardly, if not, available. Nevertheless, one indirect way of testing this hypothesis consists in running the baseline specification on a sample made up of islands and another one that includes continental countries only. In columns 1 to 3 of Table 10, the paper compares the baseline estimates with those obtained when restricting the sample to islands versus continental countries. Results suggest that the baseline estimates are indeed identified by a sub-sample of small countries for which the affected geographical areas presumably represent an important proportion of production. This findings do not mean that there are no effects of hurricanes on exports in continental countries but rather suggests that in those countries the affected areas do not represent a fraction of aggregate production that is sufficiently large to identify an effect.

The last two columns of the same table restrict the sample to countries with isolated versus frequent episodes of hurricanes. One is more likely to have a proper natural experiment and would expect larger effects in countries subject to more isolated hurricanes. For instance, countries that are hit by frequent episodes may be better prepared, have more solid infrastructures and be therefore less affected by hurricanes. Or alternatively, one could expect weaker effects in those countries because firms do not have time to adopt inefficient production structures and are constantly on an adjustment path.

To test this hypothesis, the paper separates countries with isolated from those with frequent episodes. The first sample of countries is selected as follows. A country belongs to the first sample if it only experienced one or multiple isolated episode(s) of hurricanes over the period 1980-2000, and to the second sample otherwise. An isolated episode is defined as one or multiple hurricane(s) within a time window of three years, preceded and followed by three years without hurricanes. This choice of three years is based on Yang (2008) and on the estimates of the dynamic specification obtained in the next subsection, according to which most of the adjustment takes place within three years in the aftermath of a hurricane. In this way, by leaving a window of three years before and after an episode (i.e. six years between two episodes), a country has time to adjust back to its new steady state. According to these selection criteria, the paper retains 17 countries: Bermuda, Comoros, Dominican Republic, El Salvador, France, Haiti, Hong Kong, Indonesia, Irland, Jamaica, New Zealand, Nicaragua, Saint Kitts and Nevis, Sri Lanka, Trinidad and Tobago, Thailand, United Kingdom. The same list of countries will be used later on for the event study analysis. Results suggest that the baseline estimates are indeed driven by countries with isolated episodes of hurricanes. For countries with successive hurricanes, the coefficients of interest have the expected signs but 
are smaller in magnitude and statistically insignificant, suggesting that in those countries the reallocation potential induced by one additional hurricane episode is muted and more difficult to detect. 


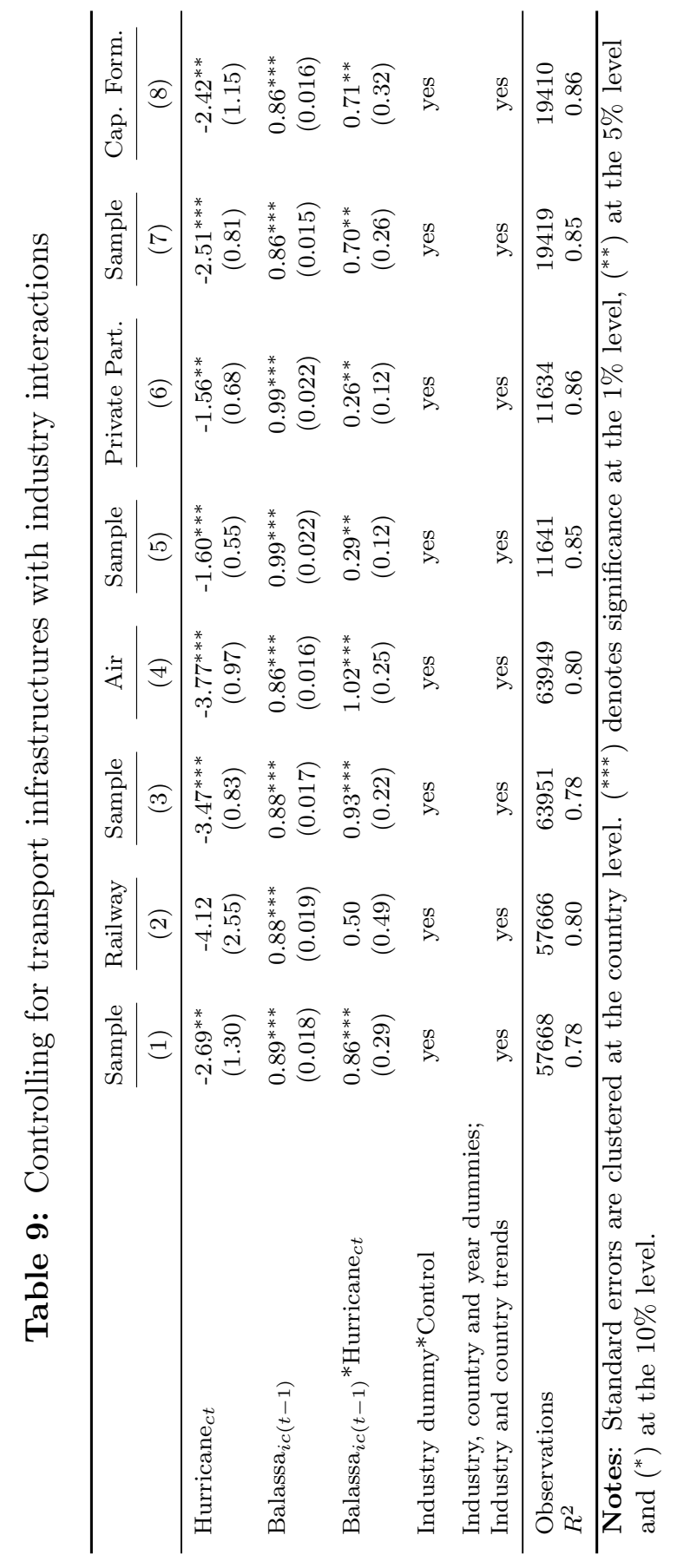




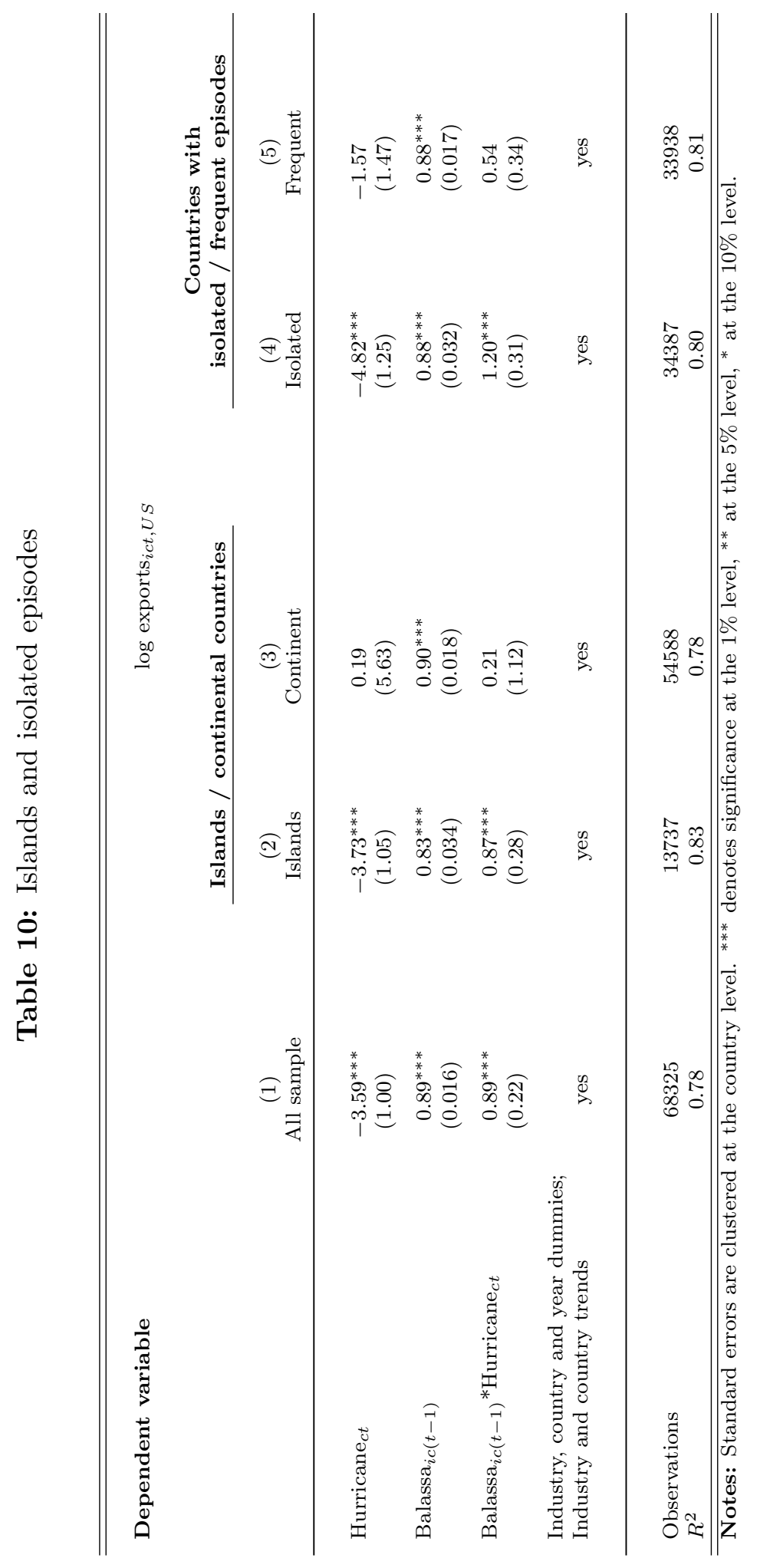




\subsection{Dynamics}

\subsubsection{Dynamic specification}

The first task in order to analyze the dynamics of the adjustment in the aftermath of a hurricane is to figure out which is the most appropriate time horizon, i.e. how long is reconstruction going to take. According to Horwich (2000), big disasters such as hurricanes, earthquakes or wars, usually have a bigger impact on physical than human capital. Moreover, in today's economies, human capital is a far more important factor of production than physical capital, and production can be achieved by a variety of combinations of factors of production. For these reasons, it does generally not take much time for economies to get back on their feet. Horwich (2000) gives several examples of economies that, after big disasters, recovered very quickly. Merely one year after the big earthquake hitting Kobe in January 1995, exports from the city were back at $85 \%$ of their pre-earthquake levels. Only 5 years after the U.S. dropped the nuclear bomb, Hiroshima was a very active city again. Another example comes from Germany. The city of Aachen was almost completely destroyed during WWII, yet it was booming again at the beginning of the 1950s. Humans are ingenious and in the aftermath of a disaster will do anything possible to go back to their former living standards. In addition, Yang (2008) shows that the bulk of the adjustment in the aftermath of a hurricane occurs within three years. For these reasons, we are confident that focusing on a relatively short time horizon allows us to capture the majority of the adjustment. Accordingly, we run a series of dynamic specifications including up to three lags of the three variables of interest. ${ }^{28}$

Table 11 reports results for these dynamic specifications. Column (1) corresponds to the static specification and columns (2), (3) and (4) show the results obtained with one lag, two and three lags. The estimates obtained in column (4) suggest that the results in column (1) capture effects that extend over several years. As can be seen, the current period estimates remain statistically significant at the $5 \%$ level at least but become smaller in magnitude. Over the years the coefficients on the hurricane index stays negative and both the Balassa measure and the interaction term remain positive.

To evaluate the dynamics of the adjustment, these estimates are used to compute the cumulative effects one, two and three years after the hurricane strike. These cumulative effects are shown at the bottom of Table 11. The magnitude of the estimate on the hurricane measure grows over time, from around -2 to -6 . This is also the case for the coefficient on the interaction term which increases from 0.6 to 1.7. These results therefore suggest that the reallocation of resources towards comparative advantage industries is a dynamic process that intensifies over a three-years period of time.

\footnotetext{
${ }^{28}$ In spite of this, we also run our dynamic specification including up to 10 lags. As expected the coefficient of interest becomes statistically insignificant from the fourth lag, confirming that reconstruction takes place right after the disaster, and generally goes very quickly.
} 
Figure 6 presents a visual representation of this process. The y-axis of the contour plot shows the number of years after the hurricane strike. Comparative advantage is shown on the $\mathrm{x}$-axis and the spectrum of colors captures the cumulative marginal effects. Bluish colors indicate a negative effects and reddish colors represent positive effects. As for the static specification, whichever year one looks at, exports are affected negatively at the bottom of the comparative advantage distribution and positively at the top, indicating a reorganization of exports towards the upper tail of the distribution. The evolution of the spectrum of colors over the years informs on the dynamics of the adjustment. The patches of intense blue in the top left corner and red in the top right corner suggest that the reallocation of resources becomes stronger over the years. The histogram of the distribution of comparative advantage reported at the bottom of the figure shows that the strong effects observed in the third year that follows the hurricane strike only affect industries at the tails of the distribution.

Finally, to gain a better understanding of what is happening to industries located at different points of the distribution of comparative advantage, Figure 7 plots the evolution of the cumulative marginal effects over the years at different percentiles of the distribution. The figure tells us that the reorganization really occurs at the bottom and top quartile of the distribution, while industries in the middle of the distribution are only minimally affected. Consistent with Figure 5 which shows that industries at both extremes of the distribution respond more abruptly, these findings suggest that the reallocation of resources towards to upper tail of the distribution is driven by far-reaching changes for firms in industries with the lowest comparative advantage. ${ }^{29}$

\footnotetext{
${ }^{29}$ In Section E of the Online Appendix we provide an analysis of the types of industrial shifts that are observed in the aftermath of a hurricane.
} 
Figure 6: Marginal effects one to three years after the hurricane
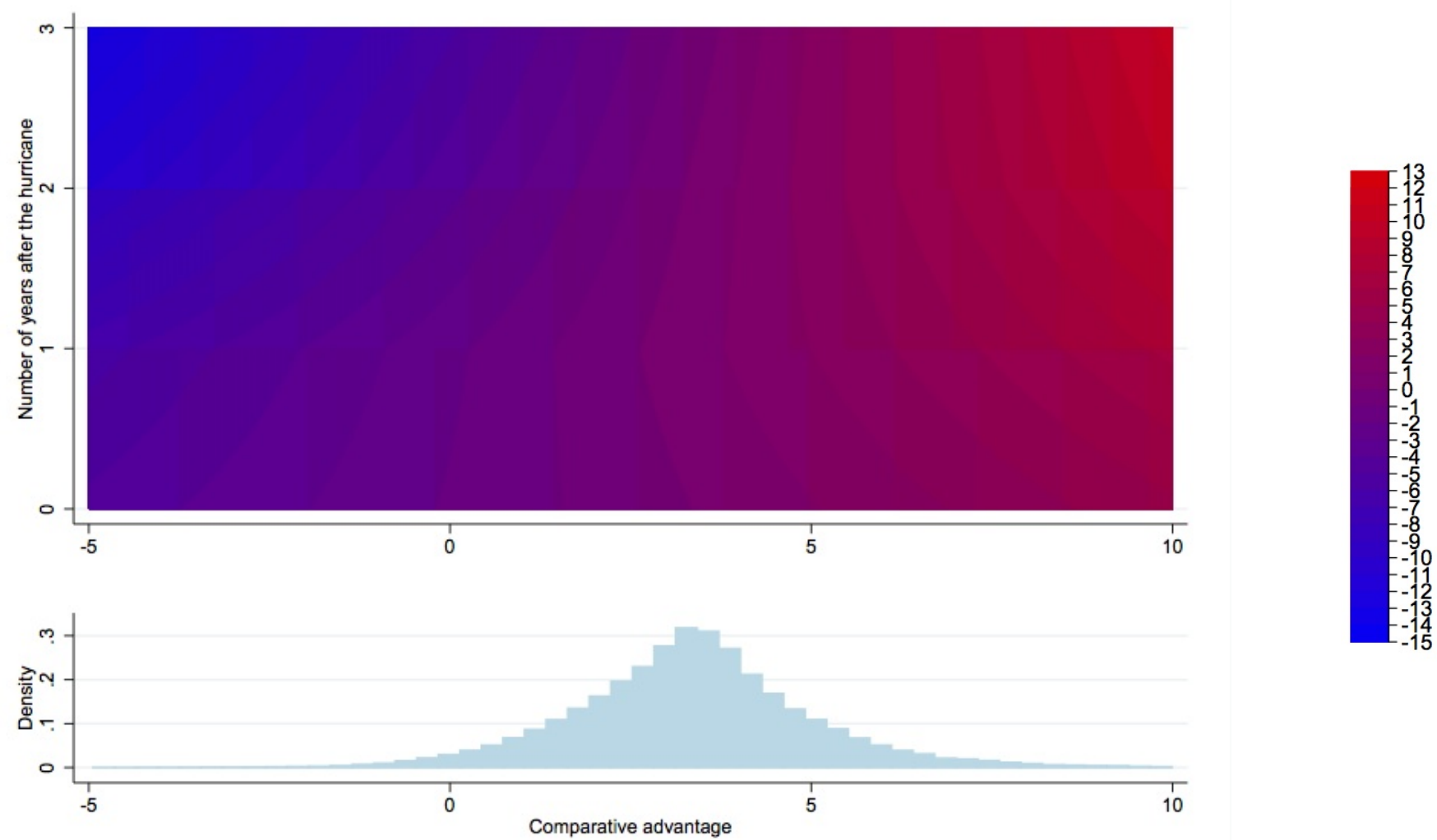
Figure 7: Marginal effects after one to three years after the hurricane

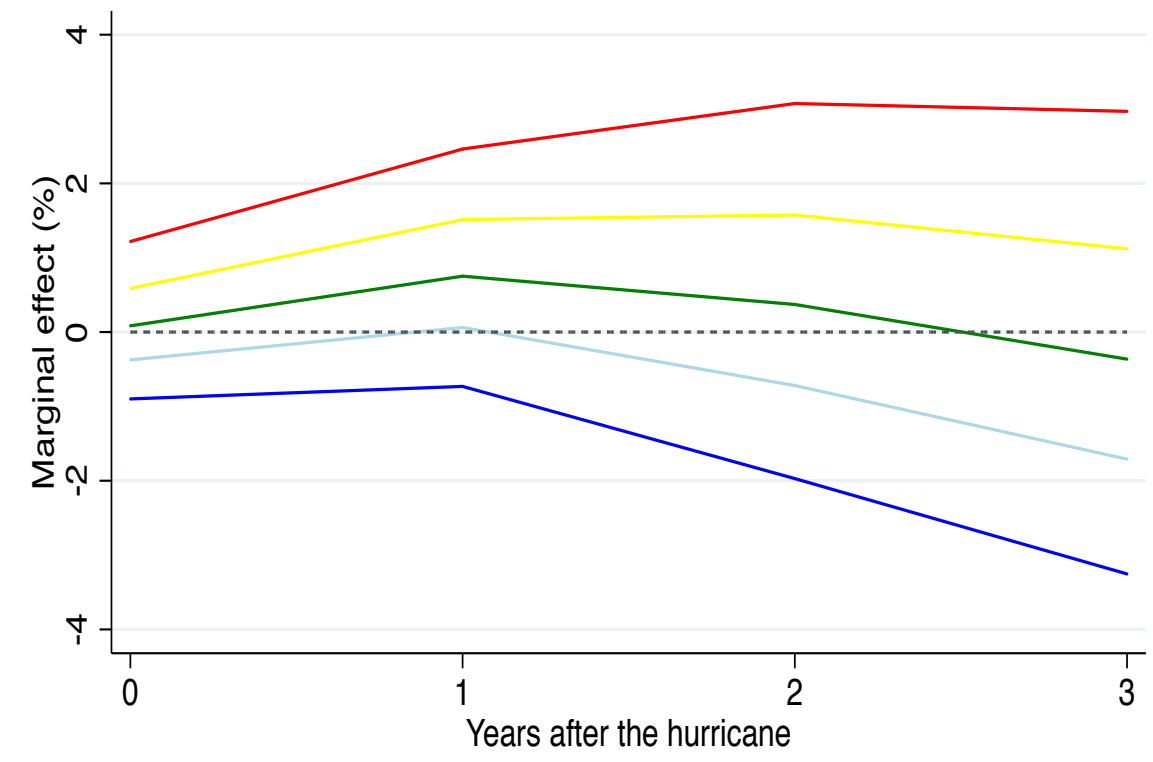

Distribution of comparative advantages

$\begin{array}{ll}\text { 10th percentile } & \text { 25th percentile } \\ \text { Median } & \text { 75th percentile } \\ \text { 90th percentile } & \end{array}$


Table 11: Dynamic specification

\begin{tabular}{|c|c|c|c|c|}
\hline & (1) & $(2)$ & (3) & (4) \\
\hline Hurricane $_{c t}$ & $\begin{array}{c}-3.59^{* * *} \\
(1.00)\end{array}$ & $\begin{array}{c}-3.17^{* * *} \\
(1.17)\end{array}$ & $\begin{array}{c}-2.38^{* *} \\
(0.97)\end{array}$ & $\begin{array}{c}-1.90^{* *} \\
(0.83)\end{array}$ \\
\hline Balassa $_{i c(t-1)}$ & $\begin{array}{c}0.89^{* * *} \\
(0.016)\end{array}$ & $\begin{array}{l}0.71^{* * *} \\
(0.024)\end{array}$ & $\begin{array}{c}0.69^{* * *} \\
(0.025)\end{array}$ & $\begin{array}{r}0.69^{* * *} \\
(0.028)\end{array}$ \\
\hline Balassa $_{i c(t-1)} *$ Hurricane $_{c t}$ & $\begin{array}{c}0.89^{* * *} \\
(0.22)\end{array}$ & $\begin{array}{c}0.82^{* * *} \\
(0.24)\end{array}$ & $\begin{array}{c}0.66^{* * *} \\
(0.20)\end{array}$ & $\begin{array}{c}0.56^{* * *} \\
(0.20)\end{array}$ \\
\hline Hurricane $_{c(t-1)}$ & & $\begin{array}{l}-1.55 \\
(1.09)\end{array}$ & $\begin{array}{l}-1.04 \\
(1.10)\end{array}$ & $\begin{array}{l}-0.34 \\
(0.93)\end{array}$ \\
\hline Balassa $_{i c(t-2)}$ & & $\begin{array}{l}0.19^{* * *} \\
(0.024)\end{array}$ & $\begin{array}{c}0.087^{* * *} \\
(0.010)\end{array}$ & $\begin{array}{r}0.080^{* * *} \\
(0.010)\end{array}$ \\
\hline Balassa $_{i c(t-2)} *$ Hurricane $_{c(t-1)}$ & & $\begin{array}{r}0.51^{* *} \\
(0.22)\end{array}$ & $\begin{array}{l}0.42^{*} \\
(0.23)\end{array}$ & $\begin{array}{c}0.29 \\
(0.22)\end{array}$ \\
\hline Hurricane $_{c(t-2)}$ & & & $\begin{array}{c}-2.42^{* * *} \\
(0.72)\end{array}$ & $\begin{array}{c}-2.11^{* * *} \\
(0.67)\end{array}$ \\
\hline Balassa $_{i c(t-3)}$ & & & $\begin{array}{c}0.13^{* * *} \\
(0.023)\end{array}$ & $\begin{array}{r}0.048^{* * *} \\
(0.011)\end{array}$ \\
\hline Balassa $_{i c(t-3)} *$ Hurricane $_{c(t-2)}$ & & & $\begin{array}{c}0.58^{* * *} \\
(0.15)\end{array}$ & $\begin{array}{c}0.49^{* * *} \\
(0.15)\end{array}$ \\
\hline Hurricane $_{c(t-3)}$ & & & & $\begin{array}{c}-1.84^{* *} \\
(0.88)\end{array}$ \\
\hline Balassa $_{i c(t-4)}$ & & & & $\begin{array}{r}0.11^{* * *} \\
(0.025)\end{array}$ \\
\hline Balassa $_{i c(t-4)} *$ Hurricane $_{c(t-3)}$ & & & & $\begin{array}{r}0.31^{* *} \\
(0.15)\end{array}$ \\
\hline $\begin{array}{l}\text { Industry, country and year dummies; } \\
\text { Industry and country trends }\end{array}$ & yes & yes & yes & yes \\
\hline \multicolumn{5}{|l|}{ Cumulative effects after : } \\
\hline $\begin{array}{l}\text { One year } \\
\text { Hurricane }\end{array}$ & & $\begin{array}{c}-4.726^{* *} \\
{[0.035]}\end{array}$ & $\begin{array}{l}-3.427^{*} \\
{[0.095]}\end{array}$ & {$\left[\begin{array}{c}-2.232 \\
0.195]\end{array}\right.$} \\
\hline Balassa & & $\begin{array}{c}0.900^{* * *} \\
{[0.000]}\end{array}$ & $\begin{array}{c}0.780^{* * *} \\
{[0.000]}\end{array}$ & $\begin{array}{c}0.771^{* * *} \\
{[0.000]}\end{array}$ \\
\hline Balassa*Hurricane & & $\begin{array}{c}1.324^{* * *} \\
{[0.004]}\end{array}$ & $\begin{array}{l}1.077^{* *} \\
{[0.012]}\end{array}$ & $\begin{array}{c}0.851^{* *} \\
{[0.039]}\end{array}$ \\
\hline $\begin{array}{l}\text { Two years } \\
\text { Hurricane }\end{array}$ & & & $\begin{array}{c}-5.850^{* *} \\
{[0.029]}\end{array}$ & $\begin{array}{r}-4.343^{*} \\
{[0.060]}\end{array}$ \\
\hline Balassa & & & $\begin{array}{c}0.914^{* * *} \\
{[0.000]}\end{array}$ & $\begin{array}{c}0.819^{* * *} \\
{[0.000]}\end{array}$ \\
\hline Balassa*Hurricane & & & $\begin{array}{c}1.655^{* * *} \\
{[0.002]}\end{array}$ & $\begin{array}{c}1.344^{* *} \\
{[0.011]}\end{array}$ \\
\hline $\begin{array}{l}\text { Three years } \\
\text { Hurricane }\end{array}$ & & & & $\begin{array}{c}-6.180^{* *} \\
{[0.010]}\end{array}$ \\
\hline Balassa & & & & $\begin{array}{c}0.932^{* * *} \\
{[0.000]}\end{array}$ \\
\hline Balassa*Hurricane & & & & $\begin{array}{l}1.658^{* * *} \\
{[0.004]}\end{array}$ \\
\hline Observations & 68325 & 65475 & 62595 & 59621 \\
\hline$R^{2}$ & 0.78 & 0.78 & 0.78 & 0.78 \\
\hline
\end{tabular}




\subsubsection{Event study}

This subsection proposes an exercise similar to that performed in Subsection 5.3.2 and evaluates the dynamics of the adjustment for countries which experienced isolated episodes of hurricanes. As in Subsection 5.3.2, one would expect the long-term effects to be more pronounced in countries with isolated hurricanes. To evaluate whether this is indeed the case, the paper adopts an event study methodology similar to the one used by Trefler (2004) and Manova (2008).

Trefler (2004) investigates the long-term effects of the Canada-U.S. Free Trade Agreement on various indicators of the Canadian economy. Manova (2008) applies the same methodology to study the impact of financial liberalization on trade flows. The main difference between the approach used in this paper and that used in Trefler (2004) and Manova (2008) resides in the definition of an event. While trade or financial liberalizations are one-time occurrences, hurricanes are repeated phenomena and thus, a country may experience more than one unique event over the period of time under consideration. In this paper, an event is defined in the exact same way as isolated episodes are defined in Subsection 5.3.2: an event consists of one or multiple hurricane(s) within a time window of three years, preceded and followed by three years without hurricanes. Table 12 lists the countries considered in the event study, the number of events in each country and the date of each event.

Table 12: Events

\begin{tabular}{lccc}
\hline \hline Country & Number of events & Event 1 & Event 2 \\
\hline Bermuda & 1 & 1995 & - \\
Comoros & 2 & 1983 & 1996 \\
Dominican Republic & 1 & 1987 & - \\
El Salvador & 2 & 1988 & 1996 \\
France & 1 & $1993-1995$ & - \\
Haiti & 1 & $1987-1988$ & - \\
Hong Kong & 1 & 1983 & - \\
Indonesia & 1 & 1983 & - \\
Irland & 2 & 1986 & - \\
Jamaica & 1 & 1988 & - \\
New Zealand & 1 & $1996-1997$ & - \\
Nicaragua & 1 & 1996 & - \\
Saint Kitts and Nevis & 1 & 1989 & - \\
Sri Lanka & 1 & 1992 & - \\
Trinidad and Tobago & 1 & 1993 & $1995-1996$ \\
Thailand & 1 & 1985 & 1986 \\
United Kingdom & 2 & & - \\
\hline \hline
\end{tabular}

The event study approach consists in estimating the following equation:

$$
\Delta \log \bar{X}_{i c \tau, U S}=\delta \Delta \bar{H}_{c \tau}+\zeta \Delta \overline{C A}_{i c \tau}+\eta \Delta\left(\bar{H}_{c \tau} * \overline{C A}_{i c \tau}\right)+\Delta v_{i c \tau}
$$


where $\delta$ and $\eta$ capture the long-term effects the paper seeks to estimate and $\Delta v_{i c \tau}$ is the error term. Since identification is achieved using a first-difference estimation, one advantage of the event study over a panel approach is that it allows one to remove all industry-country-specific unobservable effects that may interfere with the estimate of interest. $\tau$ denotes the three-years time window before and after the event and bars denote an average over the time window $\tau$. Thus, if $\tau=1(\tau=0)$ after (before) the event, then $\Delta \log \bar{X}_{i c \tau, U S}=\log \bar{X}_{i c 1, U S}-\log \bar{X}_{i c 0, U S}$, where $\bar{X}_{i c 1, U S}\left(\bar{X}_{i c 0, U S}\right)$ is the average of exports of industry $i$ in country $c$ taken over the three years following (preceding) the event. Similarly, $\Delta \overline{C A}_{i c \tau}=\overline{C A}_{i c 1}-\overline{C A}_{i c 0}$, where $\overline{C A}_{i c 1}$ $\left(\overline{C A}_{i c 0}\right)$ is the average of the Balassa measure of comparative advantage taken over the three years following (preceding) the event. Finally, $\Delta \bar{H}_{c \tau}=\bar{H}_{c 1}-0$, where $\bar{H}_{c 1}$ measures the average of the hurricane index taken over the year(s) of the event. For example, in the case of New Zealand, $\Delta \bar{H}_{c \tau}$ is given by the average of the hurricane index over the years 1996-1997.

Results are shown in Table $13 .^{30}$ The first column shows the baseline estimates, the second one shows the cumulative effects three years after the hurricane strikes and the last column presents the estimates obtained using an event study approach. The estimates obtained in the event study confirm the results of the previous subsection. The coefficient on the interaction term is statistically significant at the $1 \%$ level and remarkably similar to the one obtained from the dynamic specification (1.57 versus 1.66 ). The coefficient on the hurricane index stays negative and highly statistically significant, yet its magnitude double in the event study specification. This larger value can be explained by at least two factors. First, the vast majority of the event study countries (see Table 12) are island or other small countries where the destructive potential of hurricanes is the largest. Second, by virtue of the event study methodology, these countries experience hurricanes only sporadically. Consequently, these countries are unlikely to be adjusting to a previous hurricane at the time of the event and are more prone to larger effects. As for the Balasa index, it is not statistically significant anymore. Overall, this alternative way of investigating the long term impact of a hurricane strike confirms the results obtained in the previous subsection and suggests that the effects of interest become stronger as time passes and reconstruction gets underway.

\footnotetext{
${ }^{30}$ Controlling for alternative mechanisms such as economic growth, changes in the exchange rate, financial flows or transport infrastructures does not alter the estimates obtained in the event study.
} 
Table 13: Event study

\begin{tabular}{|c|c|c|c|}
\hline \multirow[t]{3}{*}{ Dependent variable } & \multicolumn{3}{|c|}{$\log$ exports $_{i c t, U S}$} \\
\hline & (1) & $(2)$ & (3) \\
\hline & Baseline & $\begin{array}{l}\text { Cumulative effects } \\
\text { after three years }\end{array}$ & Event study \\
\hline Hurricane $_{c t}$ & $\begin{array}{l}-3.59^{* * *} \\
(1.00)\end{array}$ & $\begin{array}{c}-6.180^{* *} \\
{[0.010]}\end{array}$ & $\begin{array}{c}-14.2^{* * *} \\
(3.66)\end{array}$ \\
\hline Balassa $_{i c(t-1)}$ & $\begin{array}{l}0.89^{* * *} \\
(0.016)\end{array}$ & $\begin{array}{l}0.932^{* * *} \\
{[0.000]}\end{array}$ & $\begin{array}{r}-0.000014 \\
(0.000075)\end{array}$ \\
\hline Balassa $_{i c(t-1)} *$ Hurricane $_{c t}$ & $\begin{array}{l}0.89^{* * *} \\
(0.22)\end{array}$ & $\begin{array}{l}1.658^{* * *} \\
{[0.004]}\end{array}$ & $\begin{array}{l}1.57^{* * *} \\
(0.46)\end{array}$ \\
\hline $\begin{array}{l}\text { Industry, country and year d } \\
\text { Industry and country trends }\end{array}$ & yes & yes & NA \\
\hline Observations & 68325 & 59621 & 2180 \\
\hline$R^{2}$ & 0.78 & 0.78 & 0.015 \\
\hline
\end{tabular}

Notes: Standard errors, in parentheses, are clustered at the country level. p-values in brackets. ${ }^{* * *}$ denotes significance at the $1 \%$ level, ${ }^{* *}$ at the $5 \%$ level, ${ }^{*}$ at the $10 \%$ level. 


\section{Conclusion}

This paper uses hurricanes to evaluate whether an exogenous shock on existing physical capital leads to a reorganization of exports towards comparative advantage industries. Our results suggest that hurricanes lead to monotone changes in export levels by comparative advantage percentiles. In particular, the marginal and total effects of hurricanes on exports are monotonically increasing in comparative advantage, with export levels decreasing at the bottom of the comparative advantage distribution and increasing at the upper tail of the distribution. We also find that industries at both extremes of the distribution respond more abruptly, while industries in the middle of the distribution are only minimally affected. These results are robust to a series of possible alternative mechanisms and alternate definition of comparative advantage. Finally, results from a dynamic specification show that the effects of hurricanes on exports are not temporary but that the process of shifting resources towards comparative advantage industries intensifies over the three-years period following a hurricane.

This paper also contributes to the literature on multiple equilibria. Our results are of particular interest in light of the results of Davis \& Weinstein $(2002,2008)$. While Japanese cities converged back to the same equilibrium after the heavy bombings suffered during WWII, the countries in our sample seem to converge towards a new equilibrium, at least in terms of export mix, in the aftermath of a hurricane. The paper also relates to the literature on the

within-country effects of extreme weather events. A large body of research studies the impact of hurricanes on, inter alia, economic growth, international financial flows, real estate markets and labor markets. This paper adds to this literature by looking at the impact of hurricanes on export patterns, a dimension that has been understudied to date. Finally, hurricanes, by virtue of their randomness, can serve the purpose of overcoming the endogeneity concerns that often plague the assessment of whether widespread adjustment policies are successful in encouraging comparative-advantage-based trade. The comparison of hurricanes to widespread adjustment policies hinges on the premise that, by destroying existing capital, hurricanes reduce the cost of adjusting to the dynamics of comparative advantage.

To conclude, it appears that the reallocation of resources towards comparative advantage industries is driven by drastic changes for firms in industries with weak comparative advantage. That is, when capital is destroyed and firms are given the opportunity for reconstruction, firms at the bottom of the distribution undertake important changes and invest in modes of production or industries that are considerably more productive or at least, in industries that have achieved great export success. Thus, if the opportunity arises, firms in comparative disadvantage industries do not stick to their current production structures but instead tend to reinvest and move up the ladder of comparative advantage. These results are consistent with the build-back better mechanism we describe in the theoretical framework and Schumpetarian creative destruction. 


\section{References}

Banerjee, A., Duflo, E., Postel-Vinay, G., \& Watts, T. (2010). Long-Run Health Impacts of Income Shocks: Wine and Phylloxera in Nineteenth-Century France. The Review of Economics and Statistics, 92(4), 714-728.

Baxter, M. (1992). Fiscal Policy, Specialization, and Trade in the Two-Sector Model: the Return of Ricardo? Journal of Political Economy, 100, 713-744.

Belasen, A. \& Polachek, S. (2008). How Hurricanes Affect Wages and Employment in Local Labor Markets. American Economic Review, 98(2), 49-53.

Bernard, A., Redding, S., \& Schott, P. (2007). Comparative Advantage and Heterogeneous Firms. Review of Economic Studies, 74(1), 31-66.

Besley, T. \& Burgess, R. (2002). The Political Economy Of Government Responsiveness: Theory And Evidence From India. The Quarterly Journal of Economics, 117(4), 14151451.

Bevere, L., Rogers, B., \& Grollimund, B. (2011). Sigma - Natural Catastrophes and ManMade Disasters in 2010: a Year of Devastating and Costly Events. Technical report, Swiss Reinsurance Company Ltd.

Blum, B. (2010). Endowments, Output, and the Bias of Directed Innovation. The Review of Economic Studies, 77, 534-559.

Braun, M. (2003). Financial Contractability and Asset Hardness. Technical report. Working Paper.

Cadot, O., Carrère, C., \& Strauss-Kahn, V. (2011). Export Diversification: What's behind the Hump? The Review of Economics and Statistics, 93(2), 590-605.

Correia, S. (2017). Linear Models with High-Dimensional Fixed Effects: an Efficient and Feasible Estimator. Technical report. Working Paper.

Costinot, A. (2009a). An Elementary Theory of Comparative Advantage. Econometrica, $77(4), 1165-1192$.

Costinot, A. (2009b). On the origins of comparative advantage. Journal of International Economics, 77(2), 255-264.

Cuaresma, J., Hlouskova, J., \& Obersteiner, M. (2008). Natural Disasters As Creative Destruction? Evidence From Developing Countries. Economic Inquiry, 46(2), 214-226. 
Davis, D. \& Weinstein, D. (2002). Bones, Bombs, and Break Points: The Geography of Economic Activity. American Economic Review, 92(5), 1269-1289.

Davis, D. \& Weinstein, D. (2008). A Search For Multiple Equilibria In Urban Industrial Structure. Journal of Regional Science, 48(1), 29-65.

Deardorff, A. (1980). The General Validity of the Law of Comparative Advantage. Journal of Political Economy, 88(5), 941-957.

Dessaint, O. \& Matray, A. (2014). Do Managers overreact to Salient Risks? Evidence from Hurricane Strikes. Technical report.

Elsner, J. (2006). Evidence in Support of the Climate Change - Altlantic Hurricane Hypothesis. Geophysical Research Letters, 33.

Elsner, J. (2007). Granger Causality and Atlantic Hurricanes. Tellus A, 59(4), 476-485.

Elsner, J. \& Bossak, B. (2001). Bayesian Analysis of U.S. Hurricane Climate. Journal of Climate, 14, 4341-4350.

Emanuel, K. (2005). Increasing Destructiveness of Tropical Cyclones Over the Past 30 Years. Nature, 436, 686-688.

Gilchrist, S. \& Williams, J. (2005). Investment, Capacity, and Uncertainty: a Putty-Clay Approach. Review of Economic Dynamics, 8, 1-27.

Groen, J. \& Polivka, A. (2008). The Effect of Hurricane Katrina on the Labor Market Outcomes of Evacuees. American Economic Review, 98(2), 43-48.

Hanson, G., Lind, N., \& Muendler, M.-A. (2016). The Dynamic of Comparative Advantage. Technical report.

Harrison, A. \& Rodríguez-Clare, A. (2010). Trade, Foreign Investment, and Industrial Policy for Developing Countries, volume 5 of Handbook of Development Economics, (pp. 40394214). Elsevier.

Horwich, G. (2000). Economic Lessons of the Kobe Earthquake. Economic Development and Cultural Change, 48(3), 521-542.

Hoyos, C., Agudelo, P., Webster, P., \& Curry, J. (2006). Deconvolution of the Factors Contributing to the Increase in Global Hurricane Intensity. Science, (pp. 94-97).

Hsiang, S. (2010). Temperatures and cyclones strongly associated with economic production in the Caribbean and Central America. Proceedings of the National Academy of Sciences, 107(35), 15367-15372. 
Hsiang, S. \& Jina, A. (2014). The Causal Effect of Environmental Catastrophe on Long-Run Economic Growth: Evidence From 6,700 Cyclones. NBER Working Papers 20352, National Bureau of Economic Research, Inc.

Hsiang, S., Meng, K., \& Cane, M. (2011). Civil Conflicts are associated with the Global Climate. Nature, 476, 438-441.

Hsiang, S. \& Narita, D. (2012). Adaptation To Cyclone Risk: Evidence From The Global Cross-Section. Climate Change Economics (CCE), 3(02), 1250011-1-1.

Imbs, J. \& Wacziarg, R. (2003). Stages of Diversification. American Economic Review, 93(1), $63-86$.

Ishise, H. (2016). Capital Heterogeneity as a Source of Comparative Advantage: Putty-Clay Technology in a Ricardian Model. Journal of International Economics, 99, 223-236.

Levchenko, A. (2007). Institutional Quality and International Trade. Review of Economic Studies, 74(3), 791-819.

Lindell, M., Prater, C., \& Perry, R. (2007). Introduction to Emergency Management. Wiley.

Maccini, S. \& Yang, D. (2009). Under the Weather: Health, Schooling, and Economic Consequences of Early-Life Rainfall. American Economic Review, 99(3), 1006-26.

Manova, K. (2008). Credit Constraints, Equity Market Liberalizations and International Trade. Journal of International Economics, 76(1), 33-47.

Melitz, M. (2003). The Impact of Trade on Intra-Industry Reallocations and Aggregate Industry Productivity. Econometrica, 71(6), 1695-1725.

Miguel, E. \& Roland, G. (2011). The long-run impact of bombing Vietnam. Journal of Development Economics, 96(1), 1-15.

Nunn, N. (2007). Relationship-Specificity, Incomplete Contracts, and the Pattern of Trade. The Quarterly Journal of Economics, 122(2), 569-600.

OECD (2011). Globalisation, Comparative Advantage and the Changing Dynamics of Trade. Publishing.

Pielke, R., Landsea, C., Mayfield, M., Laver, J., \& Pasch, R. (2008). Hurricanes and Global Warming. American Meteorological Society, (pp. 1571-1575).

Raddatz, C. (2006). Liquidity Needs and Vulnerability to Financial Underdevelopment. Journal of Financial Economics, 80, 677-722. 
Rajan, R. \& Zingales, L. (1998). Financial Dependence and Growth. American Economic Review, 88(3), 559-86.

Redding, S. (1999). Dynamic Comparative Advantage and the Welfare Effects of Trade. Oxford Economic Papers, 51, 15-39.

Rodrik, D. (2009). Industrial Policy: Don'T Ask Why, Ask How. Middle East Development Journal (MEDJ), 1(01), 1-29.

Scott, P., Stone, D., \& Allen, M. (2004). Human Contribution to the European Heatwave of 2003. Nature, 432, 610-614.

Skidmore, M. \& Toya, H. (2002). Do Natural Disasters Promote Long-Run Growth? Economic Inquiry, 40(4), 664-687.

Stern, N. (2007). The Economics of Climate Change: The Stern Review. Cambridge University Press.

Strömberg, D. (2007). Natural Disasters, Economic Development, and Humanitarian Aid. Journal of Economic Perspectives, 21(3), 199-222.

Trefler, D. (2004). The Long and Short of the Canada-U. S. Free Trade Agreement. American Economic Review, 94(4), 870-895.

Udry, C. (1994). Risk and Insurance in a Rural Credit Market: An Empirical Investigation in Northern Nigeria. Review of Economic Studies, 61(3), 495-526.

Webster, P., Holland, G., Curry, J., \& Chang, H.-R. (2005). Changes in Tropical Cyclone Number, Duration, and Intensity in a Warming Environment. Science, 309(5742), 18441846.

Wu, H. \& Lindell, M. (2014). Perceptions ofn Hurricane Information and Protective Action Decisions. Technical report, XVIII ISA World Congress of Sociology.

Yang, D. (2008). Coping with Disaster: The Impact of Hurricanes on International Financial Flows, 1970-2002. The B.E. Journal of Economic Analysis and Policy, 8(2).

Young, A. (1991). Learning by Doing and the Dynamic Effects of International Trade. The Quarterly Journal of Economics, 106(2), 369. 


\section{A Appendix. Figures}

Figure A.1: India best tracks, 1970-2005

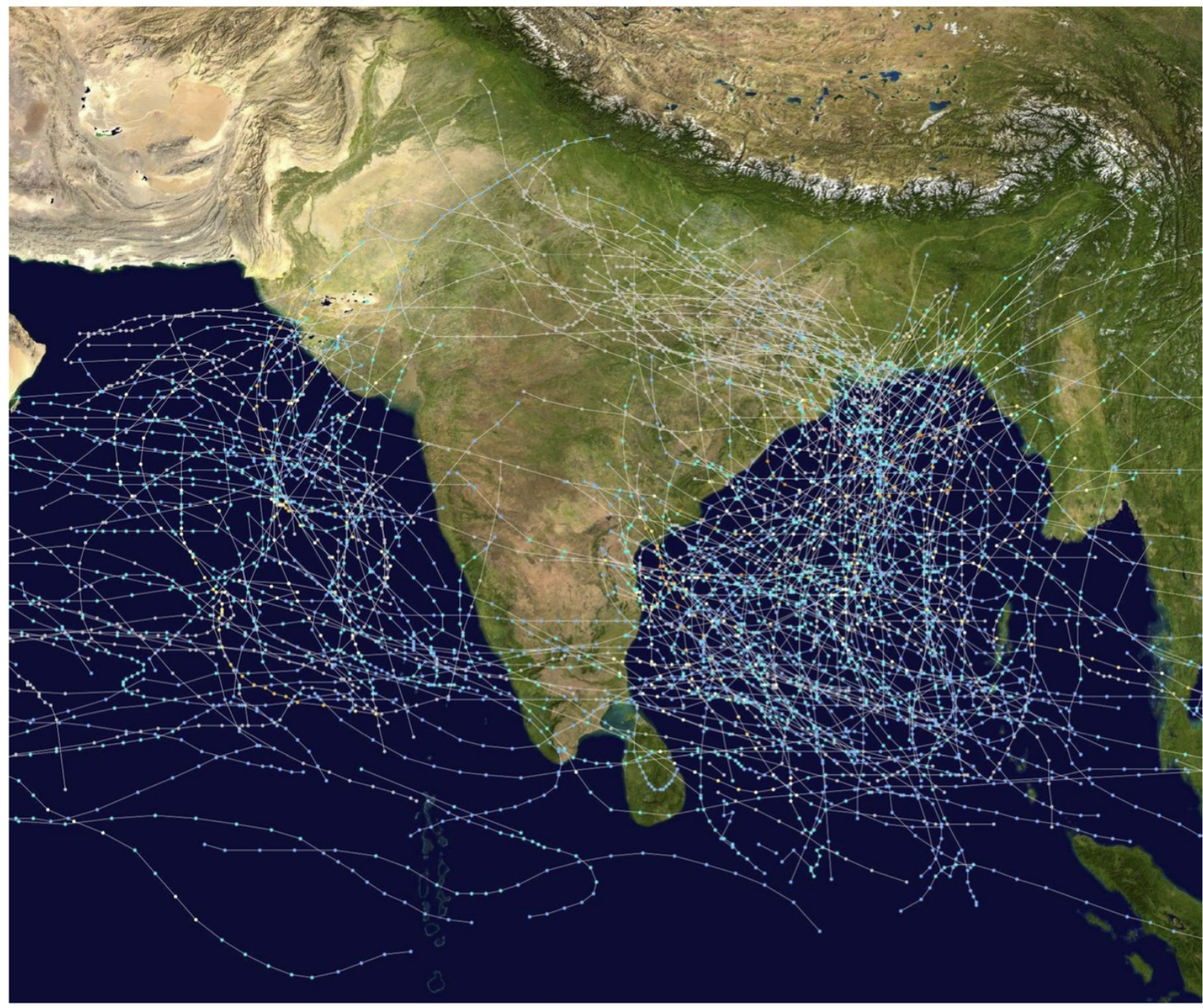

Notes: The figure shows the tracks of all tropical cyclones over India between 1970 and 2005. Source: National Hurricane Center (NOAA). 
Figure A.2: India firms' location, 1995

All Firms in 1995

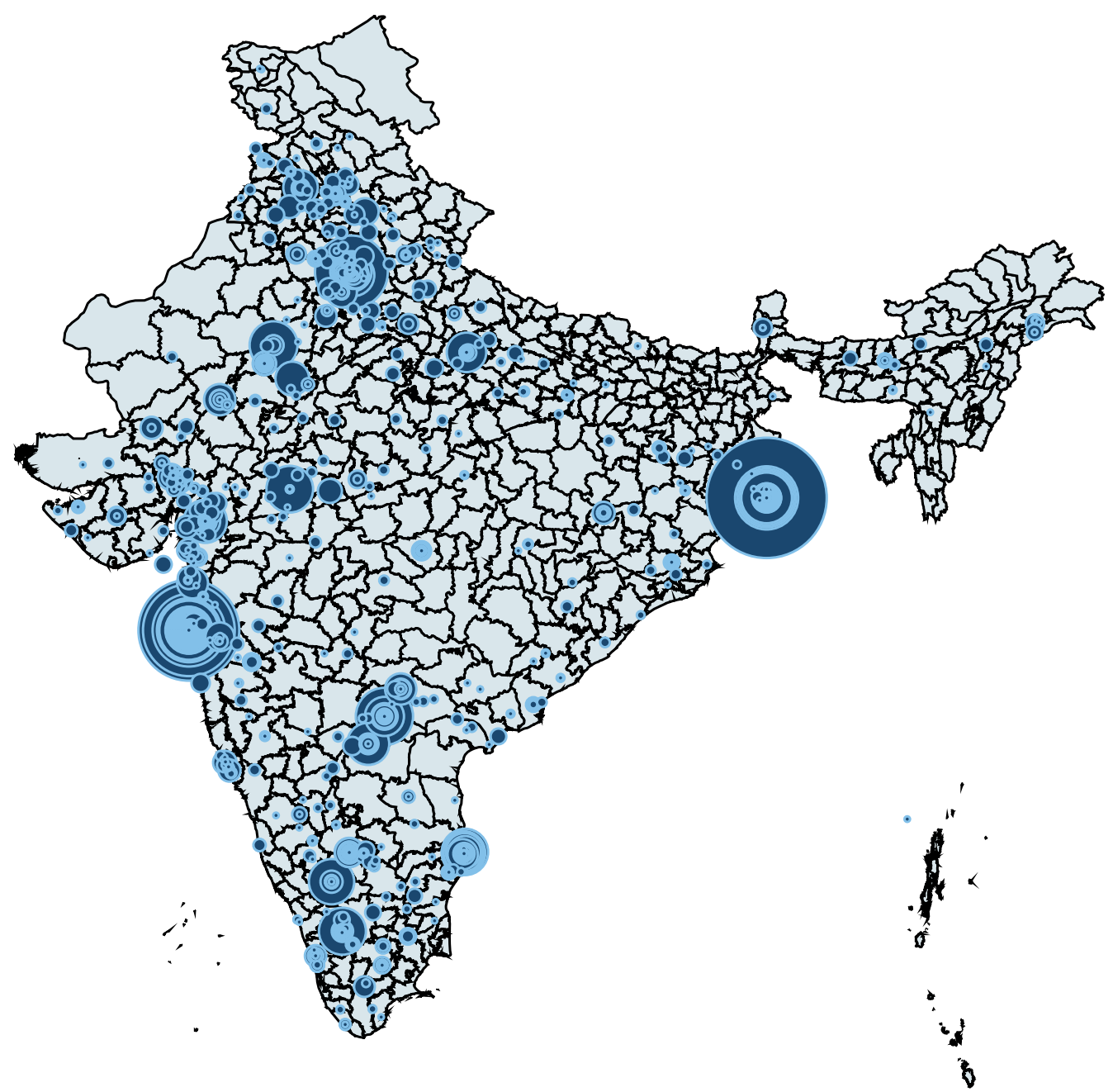

Notes: The figure shows the location of firms included in the PROWESS database for 1995. The diameter of the circles is proportional to the number of firms in a given PIN code (the equivalent of an Indian ZIP code). Source: PROWESS and authors calculations. 
Figure A.3: Northwestern Pacific Ocean best tracks, 1980-2005

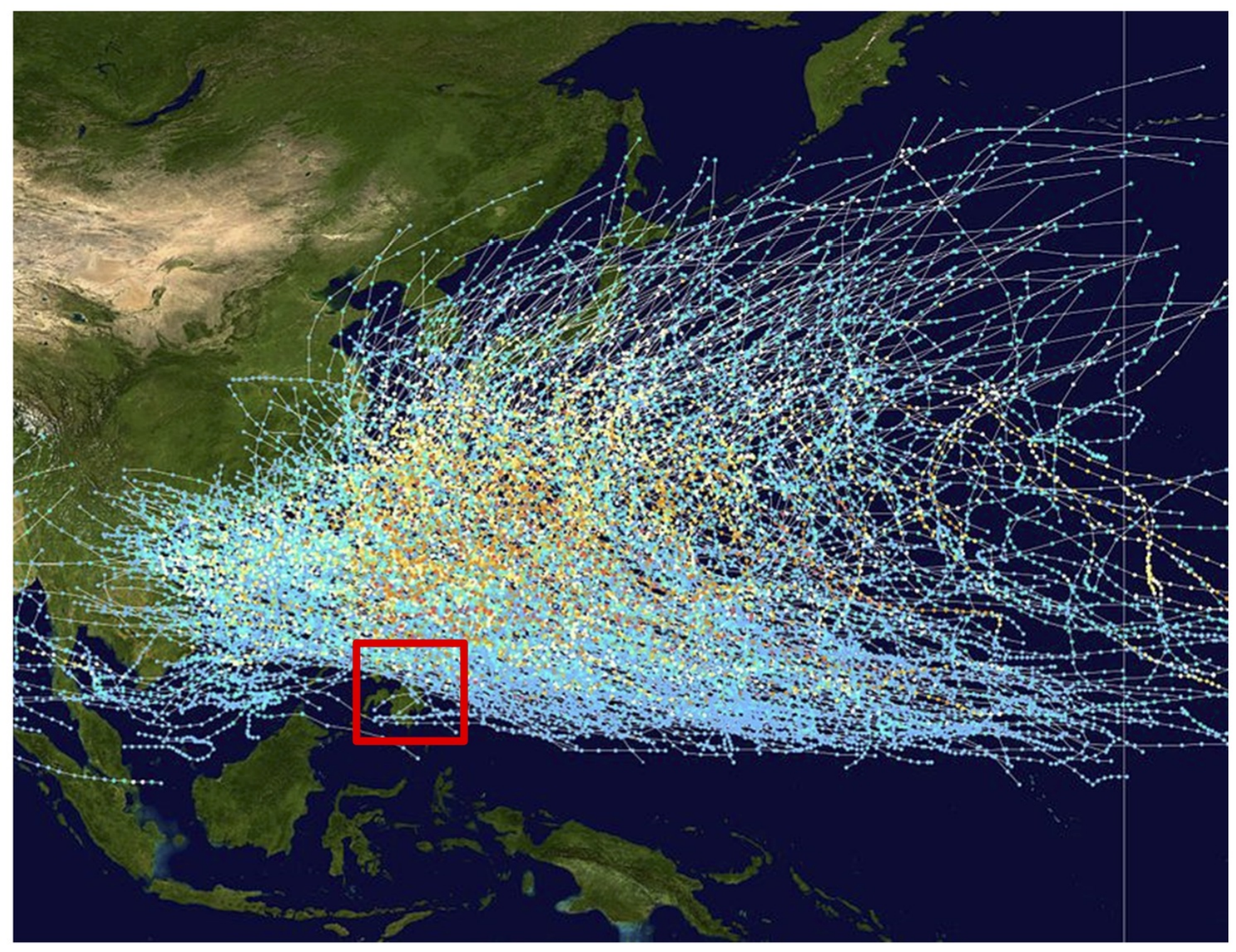

Notes: The figure shows the tracks of all tropical cyclones in the northernwestern Pacific Ocean between 1980 and 2005. The vertical line to the right is the International Date Line. Source: National Hurricane Center (NOAA). 
Figure A.4: Philippines gross value added in the manufacturing sector, 2012

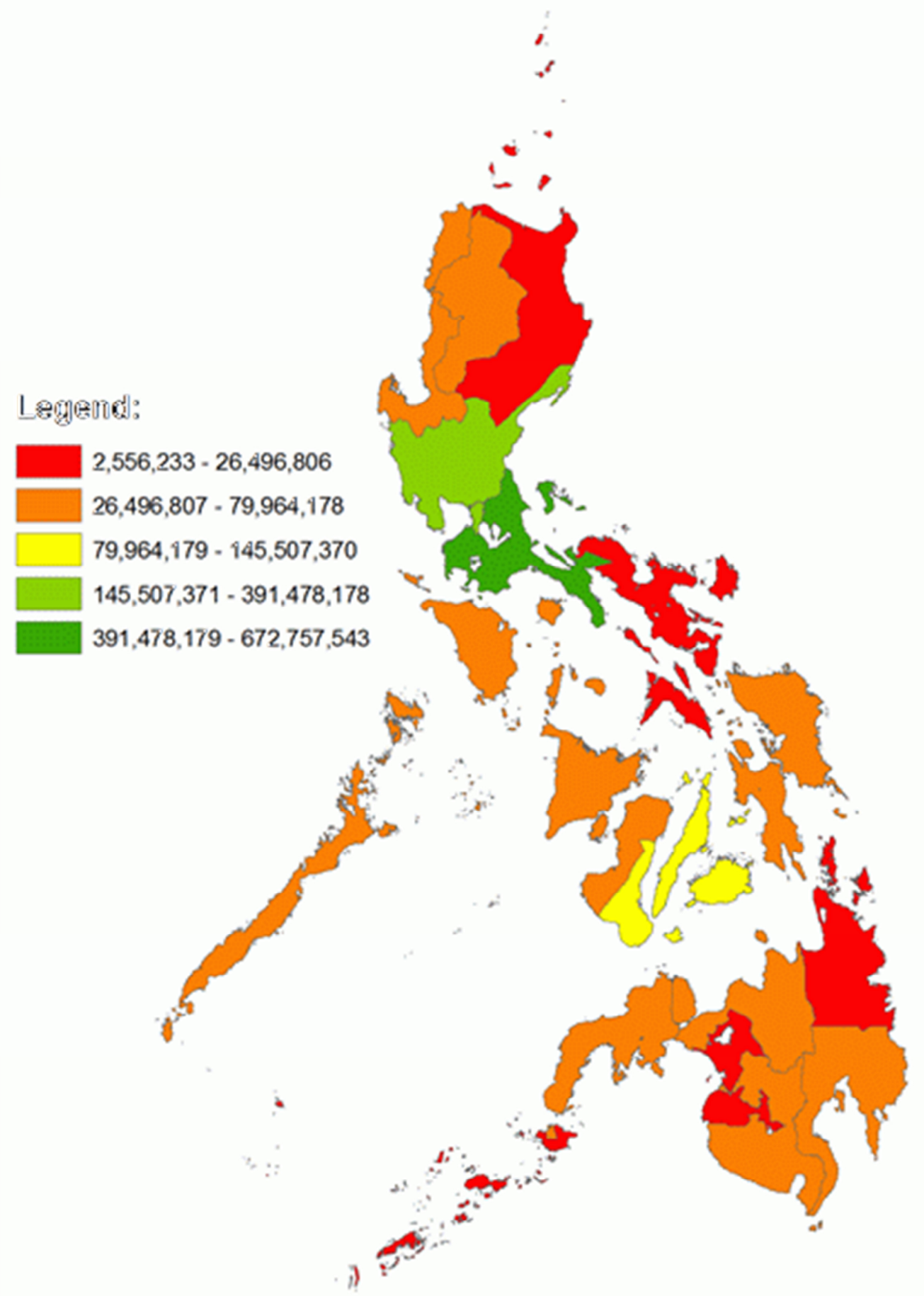

Source: http://www.nscb.gov.ph/grdp/2012/dataCharts/default.asp. 
Figure A.5: Distribution of the Balassa measure of comparative advantage

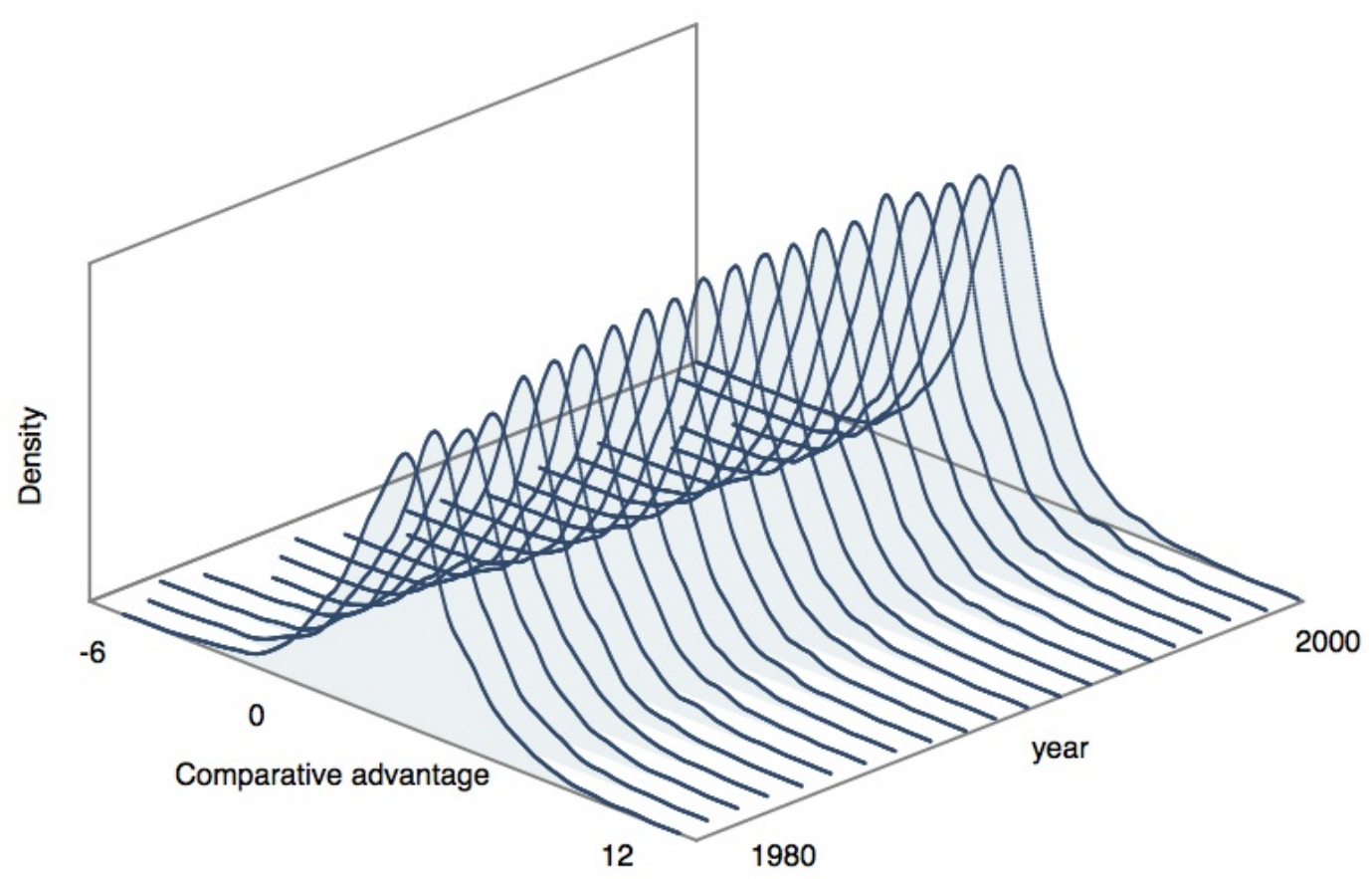

Figure A.6: Total effects

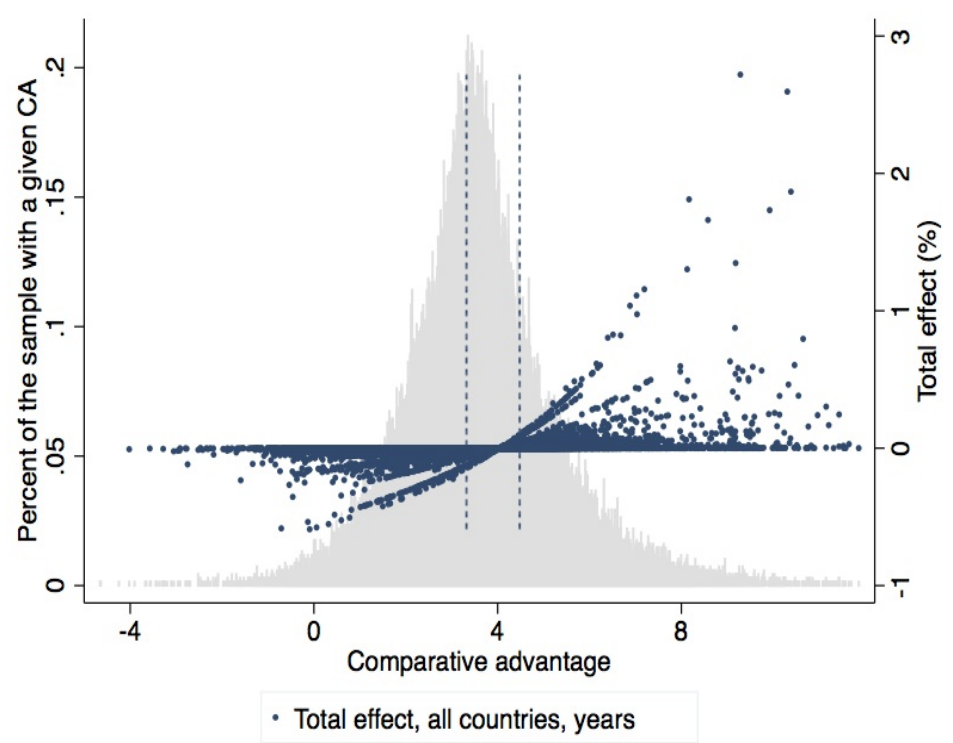




\section{B Appendix. Tables}

Table B.1: Isocodes

\begin{tabular}{llll}
\hline \hline Country & Isocode & Country & Isocode \\
\hline Bahamas & & & \\
Bangladesh & BHS & Malaysia & MYS \\
Barbados & BGD & Mauritius & MUS \\
Bermuda & BRB & Mexico & MEX \\
China & BMU & Myanmar & MMR \\
Colombia & CHN & New Caledonia & NCL \\
Comoros & COL & New Zealand & NZL \\
Costa Rica & COM & Nicaragua & NIC \\
Cuba & CRI & Oman & OMN \\
Dominican Republic & CUB & Pakistan & PAK \\
El Salvador & SLV & Philippines & PHL \\
Fiji & FJI & Portugal & PRT \\
France & FRA & Republic of Korea & KOR \\
Guatemala & GTM & Saint Kitts and Nevis & RUS \\
Haiti & HTI & Saudi Arabia & SAU \\
Honduras & HND & Spain & ESP \\
Hong Kong & HKG & Sri Lanka & LKA \\
Iceland & ISL & Thailand & THA \\
India & IND & Trinidad and Tobago & TTO \\
Indonesia & IDN & United Kingdom & GBR \\
Ireland & IRL & Venezuela & VEN \\
Jamaica & JAM & Vietnam & VNM \\
Madagascar & MDG & Zimbabwe & ZWE \\
\hline \hline
\end{tabular}


Table B.2: Share of manufacturing exports in total exports and of manufacture production in GDP, by country over the period 1980-2000.

\begin{tabular}{|c|c|c|c|c|c|c|c|c|}
\hline \multirow[b]{2}{*}{ Country } & \multicolumn{4}{|c|}{$\begin{array}{l}\text { Manufacturing exports } \\
\text { over total exports }\end{array}$} & \multicolumn{4}{|c|}{ Manufacturing over GDP } \\
\hline & Mean & Std. Dev. & Min. & Max. & Mean & Std. Dev. & Min. & Max. \\
\hline All 46 countries & 48.94 & 28.35 & 0.69 & 98.42 & 17.28 & 7.53 & 0.4 & 40.5 \\
\hline Bahamas & 53.5 & 27.2 & 8.5 & 80.4 & $N A$ & $N A$ & $N A$ & $N A$ \\
\hline Bangladesh & 76.2 & 12.8 & 57.8 & 91.8 & 14.4 & 1.0 & 12.8 & 16.2 \\
\hline Barbados & 63.8 & 12.1 & 45.1 & 84.7 & 10.0 & 1.5 & 6.4 & 12.7 \\
\hline Bermuda & 67.9 & 25.2 & 29.8 & 98.4 & $N A$ & $N A$ & $N A$ & $N A$ \\
\hline China & 73.3 & 17.4 & 48.6 & 92.3 & 34.5 & 2.2 & 31.6 & 40.5 \\
\hline Colombia & 23.3 & 5.8 & 12.9 & 30.8 & 19.6 & 3.1 & 14.8 & 23.9 \\
\hline Comoros & 22.5 & 20.5 & 8.7 & 81.5 & 4.0 & 1.0 & 0.4 & 6.0 \\
\hline Costa Rica & 33.8 & 12.5 & 17.3 & 61.7 & 23.5 & 1.8 & 21.1 & 29 \\
\hline Cuba & 15.4 & 5.0 & 2.7 & 25.8 & 37.1 & 1.1 & 35.6 & 38.7 \\
\hline Dominican Republic & 63.6 & 20.8 & 32.4 & 90.4 & 16.6 & 2.3 & 12.1 & 18.9 \\
\hline El Salvador & 40.5 & 22.7 & 9.2 & 81.5 & 23.3 & 0.9 & 22.1 & 24.7 \\
\hline Fiji & 21.0 & 15.1 & 4.8 & 47.8 & 12.4 & 2.0 & 9.2 & 15.1 \\
\hline France & 82.0 & 2.3 & 77.9 & 86.7 & 16.1 & 0.1 & 16 & 16.1 \\
\hline Guatemala & 27.7 & 13.9 & 5.5 & 49.6 & 14.9 & 1.0 & 13.2 & 16.6 \\
\hline Haiti & 79.1 & 7.1 & 63.3 & 89.2 & 12.8 & 3.8 & 9.0 & 20 \\
\hline Honduras & 32.7 & 23.8 & 9.9 & 75.1 & 16.5 & 1.8 & 14.3 & 19.6 \\
\hline Hong Kong & 93.5 & 3.5 & 81.2 & 95.4 & 14.8 & 6.9 & 5.3 & 23.4 \\
\hline India & 68.2 & 10.1 & 49.8 & 80.2 & 16.4 & 0.7 & 14.8 & 17.9 \\
\hline Indonesia & 35.8 & 20.8 & 4.9 & 61.8 & 19.9 & 5.2 & 11.9 & 27.7 \\
\hline Iceland & 23.2 & 3.4 & 17.3 & 31.2 & 15.0 & 1.2 & 14.0 & 16.4 \\
\hline Ireland & 71.7 & 8.3 & 57.8 & 87.8 & 31.8 & 2.2 & 29.0 & 34.3 \\
\hline Jamaica & 39.1 & 9.3 & 14.9 & 52.7 & 15.3 & 1.4 & 13.7 & 17.2 \\
\hline Madagascar & 19.3 & 13.7 & 5.7 & 46.3 & 10.8 & 1.3 & 7.9 & 12.9 \\
\hline Mexico & 59.2 & 20.8 & 24.3 & 83.6 & 21.7 & 1.8 & 18.7 & 26.4 \\
\hline Myanmar & 19.0 & 12.5 & 7 & 55 & 7.9 & 1.3 & 6.2 & 9.9 \\
\hline Mauritius & 57.7 & 15.7 & 25.1 & 74.8 & 21.9 & 3.4 & 15.7 & 25.5 \\
\hline Malaysia & 61.9 & 18.9 & 37.4 & 86.8 & 24.2 & 4.2 & 19.1 & 32.6 \\
\hline New Caledonia & 66.8 & 4.4 & 58.6 & 74.1 & 4.5 & 0.3 & 4.0 & 4.8 \\
\hline New Zealand & 28.2 & 3.8 & 23 & 34.6 & 18.7 & 1.5 & 16.6 & 22.1 \\
\hline Nicaragua & 15.3 & 15.9 & 0.7 & 44.8 & 17.8 & 0.9 & 16.4 & 18.9 \\
\hline Oman & 8.9 & 6.3 & 2.2 & 24 & 3.4 & 1.2 & 0.6 & 5.4 \\
\hline Pakistan & 71.5 & 12.1 & 49.6 & 86 & 16.1 & 0.7 & 14.7 & 17.4 \\
\hline Philippines & 70.3 & 14.8 & 43.7 & 91.6 & 24.1 & 1.3 & 21.6 & 25.7 \\
\hline Portugal & 83.5 & 4.2 & 75.3 & 89.2 & 18.4 & 0.7 & 17.1 & 19.2 \\
\hline Republic of Korea & 91.5 & 1.4 & 87.8 & 93.2 & 27.4 & 1.6 & 24.4 & 30.7 \\
\hline Russia & 30.4 & 9.2 & 15.5 & 46.8 & $N A$ & $N A$ & $N A$ & $N A$ \\
\hline Saint Kitts and Nevis & 40.5 & 12.9 & 23.1 & 65.4 & 12.4 & 1.9 & 9.9 & 15.4 \\
\hline Saudi Arabia & 6.6 & 3.8 & 0.8 & 13.9 & 8.4 & 1.9 & 4.1 & 10.6 \\
\hline Spain & 77.8 & 2.9 & 73.6 & 81.9 & 18.6 & - & 18.6 & 18.6 \\
\hline Sri Lanka & 61.5 & 22.4 & 19.7 & 84.3 & 15.6 & 0.9 & 14 & 17.7 \\
\hline Thailand & 57.6 & 16.5 & 32.4 & 78.1 & 26.8 & 3.9 & 21.3 & 33.6 \\
\hline Trinidad and Tobago & 31.5 & 18.1 & 4.6 & 60 & 9.6 & 1.9 & 7.3 & 14.0 \\
\hline United Kingdom & 78.1 & 6.6 & 65.8 & 85 & 22.7 & 2.4 & 17.9 & 26.5 \\
\hline Venezuela & 13.7 & 6.1 & 4.8 & 23.6 & 17.2 & 2.5 & 13.6 & 23.2 \\
\hline Vietnam & 28.7 & 19.1 & 7.3 & 55.5 & 16.9 & 3.0 & 12.3 & 22.4 \\
\hline Zimbabwe & 63.8 & 5.3 & 49.38 & 73.3 & 21.5 & 3.4 & 15.8 & 29.5 \\
\hline
\end{tabular}

Note: Source: World Bank Development Indicators 2009 and NBER United Nations trade data. For manufacturing over GDP, the summary statistics are computed over available years for the period 1980-2000. Missing means no data were available. 
Table B.4: Share of US exports in total exports, by country over the period 1980-2000.

\begin{tabular}{|c|c|c|c|c|}
\hline Country & Mean & Std. Dev. & Min. & Max. \\
\hline All 46 countries & 27.72 & 24.11 & 0 & 91.98 \\
\hline Bahamas & 50.1 & 18.7 & 25.2 & 86.9 \\
\hline Bangladesh & 31.3 & 9.7 & 11.6 & 41 \\
\hline Barbados & 48.1 & 18.1 & 24 & 86.4 \\
\hline Bermuda & 9.1 & 8.2 & 0.9 & 25.6 \\
\hline China & 17.7 & 5.6 & 6.8 & 27.0 \\
\hline Colombia & 38.8 & 6.8 & 26.0 & 51.1 \\
\hline Comoros & 9.2 & 6.9 & 1.7 & 31.9 \\
\hline Costa Rica & 54.7 & 8.4 & 34.1 & 63.6 \\
\hline Cuba & 0.0 & 0.0 & 0.0 & 0.2 \\
\hline Dominican Republic & 81.4 & 12.2 & 48.9 & 91.3 \\
\hline El Salvador & 60.9 & 14.2 & 30.8 & 84.9 \\
\hline Fiji & 12.5 & 6.0 & 4.1 & 27.9 \\
\hline France & 7.4 & 1.3 & 5.0 & 10.3 \\
\hline Guatemala & 57.6 & 15.0 & 24.4 & 74.4 \\
\hline Haiti & 82.6 & 5.8 & 70.1 & 92 \\
\hline Honduras & 63.1 & 11.3 & 48.8 & 84 \\
\hline Hong Kong & 26.9 & 8.7 & 17.9 & 44.6 \\
\hline India & 20.8 & 4.1 & 15.7 & 34.5 \\
\hline Indonesia & 17.9 & 4.4 & 11.1 & 27.9 \\
\hline Iceland & 17.9 & 6.6 & 10.6 & 30.6 \\
\hline Ireland & 9.6 & 3.6 & 4.8 & 20.9 \\
\hline Jamaica & 45.7 & 5.8 & 35.6 & 58.8 \\
\hline Madagascar & 14.7 & 4.9 & 5.2 & 23 \\
\hline Malaysia & 17.8 & 3.1 & 13.6 & 23.1 \\
\hline Mauritius & 14.5 & 3.8 & 5.6 & 20.1 \\
\hline Mexico & 74.1 & 6.4 & 61.8 & 83.2 \\
\hline Myanmar & 7.3 & 6.8 & 2.0 & 29.4 \\
\hline New Caledonia & 8.3 & 1.9 & 5.7 & 13.1 \\
\hline New Zealand & 13.5 & 1.7 & 10.4 & 17.4 \\
\hline Nicaragua & 35.0 & 26.2 & 0.0 & 72.1 \\
\hline Oman & 4.8 & 3.3 & 1.0 & 12.3 \\
\hline Pakistan & 13.1 & 5.3 & 5.1 & 25.3 \\
\hline Philippines & 35.7 & 3.6 & 27.7 & 42.1 \\
\hline Portugal & 6.1 & 1.6 & 3.7 & 10.0 \\
\hline Republic of Korea & 28.8 & 8.5 & 18.1 & 45.4 \\
\hline Russia & 3.2 & 2.4 & 0.9 & 7.6 \\
\hline Saint Kitts and Nevis & 21.8 & 5.7 & 15.7 & 39.5 \\
\hline Saudi Arabia & 12.6 & 3.3 & 3.7 & 17.7 \\
\hline Spain & 6.8 & 2.1 & 4.6 & 11.1 \\
\hline Sri Lanka & 32.2 & 10.0 & 11.5 & 45.9 \\
\hline Thailand & 20.2 & 3.7 & 12.6 & 24.1 \\
\hline Trinidad and Tobago & 67.0 & 7.0 & 52.2 & 78.9 \\
\hline United Kingdom & 12.8 & 1.8 & 9.5 & 15.4 \\
\hline Venezuela & 50.3 & 8.2 & 32.5 & 58.6 \\
\hline Vietnam & 1.5 & 2.5 & 0.0 & 6.5 \\
\hline Zimbabwe & 9.5 & 2.7 & 6.5 & 17.2 \\
\hline
\end{tabular}


Table B.3: Summary statistics of comparative advantage measures, by country over the period 1980-2000.

\begin{tabular}{|c|c|c|c|c|c|c|c|c|c|}
\hline \multirow[b]{2}{*}{ Country } & \multicolumn{4}{|c|}{ Log Balassa } & \multicolumn{4}{|c|}{ Hanson et al. } & \multirow[b]{2}{*}{$\mathbf{N}$} \\
\hline & Mean & Std. Dev. & Min. & Max. & Mean & Std. Dev. & Min. & Max. & \\
\hline All & 3.3 & 1.7 & -5.9 & 12.1 & 1.2 & 1.7 & -5.5 & 15.0 & 105,183 \\
\hline Bahamas & 6.9 & 2.3 & -1.7 & 10.3 & -0.4 & 1.5 & -4.8 & 2.6 & 105 \\
\hline Bangladesh & 7 & 2.6 & 1.6 & 11.9 & 1 & 1.4 & -1.5 & 5.2 & 210 \\
\hline Barbados & 7.8 & 1.4 & 5.2 & 10.5 & -0.7 & 0.9 & -2.7 & 1.4 & 63 \\
\hline Bermuda & 7.3 & 1.1 & 4.5 & 9.4 & -1.3 & 0.8 & -2.8 & 0.4 & 63 \\
\hline China & 3.3 & 1.7 & -4.9 & 7.7 & 2.3 & 1.8 & -3.2 & 8.5 & 6153 \\
\hline Colombia & 4.6 & 1.5 & -3 & 9.1 & 0.3 & 1.2 & -3.5 & 4.8 & 1911 \\
\hline Comoros & 10.9 & 0.6 & 9.7 & 11.6 & -0.3 & 0.6 & -1.4 & 0.7 & 21 \\
\hline Costa Rica & 5.3 & 1.7 & -0.5 & 10.2 & -0.5 & 1 & -3.4 & 4.1 & 462 \\
\hline Cuba & 7.6 & 2.5 & 4.2 & 12.1 & 0.3 & 1.3 & -2.5 & 3.5 & 84 \\
\hline Dominican Republic & 4.9 & 2.1 & -3.2 & 9.6 & -0.5 & 1.4 & -3.7 & 4.5 & 672 \\
\hline El Salvador & 6.3 & 1.3 & 3.6 & 8.2 & -0.9 & 0.9 & -2.7 & 1.3 & 147 \\
\hline Fiji & 10.1 & 1 & 7.2 & 11.6 & 0.6 & 1 & -1.2 & 3.6 & 42 \\
\hline France & 3.2 & 0.9 & -2.6 & 6.1 & 2.2 & 1.4 & -1.7 & 7.3 & 9702 \\
\hline Guatemala & 7 & 1.4 & 2.3 & 9.4 & -0.7 & 1 & -2.7 & 3.3 & 189 \\
\hline Haiti & 5.7 & 1.5 & 0.4 & 9.1 & -0.9 & 1.3 & -5.5 & 1.5 & 315 \\
\hline Honduras & 7.1 & 1.8 & 1.6 & 10.2 & 0 & 1.1 & -2.6 & 3.5 & 252 \\
\hline Hong Kong & 3 & 1.7 & -5.1 & 7.2 & 1.5 & 1.6 & -2.9 & 6.3 & 5544 \\
\hline Iceland & 5.7 & 2.3 & -1.3 & 10.9 & -0.5 & 1.5 & -5.4 & 4.1 & 252 \\
\hline India & 3.2 & 1.8 & -5.1 & 8.4 & 1.1 & 1.5 & -2.2 & 7.2 & 4872 \\
\hline Indonesia & 4 & 2 & -5.1 & 9 & 2 & 1.9 & -2.4 & 7.5 & 1827 \\
\hline Ireland & 3 & 1.6 & -3.5 & 7.2 & -0.5 & 1.3 & -4.9 & 5.5 & 5187 \\
\hline Jamaica & 6.8 & 1.8 & 1.7 & 10.1 & 0 & 1.4 & -3.7 & 4.1 & 147 \\
\hline Madagascar & 8.4 & 1.4 & 5.5 & 11 & 1.3 & 1.2 & -1.4 & 3.6 & 84 \\
\hline Malaysia & 2.7 & 1.7 & -4.6 & 8.5 & 0.9 & 1.7 & -3.4 & 8.1 & 4263 \\
\hline Mauritius & 6 & 1.2 & 3.5 & 9.5 & 0.1 & 1.1 & -2.4 & 3.4 & 231 \\
\hline Mexico & 3 & 1.5 & -4.2 & 7.6 & 0.8 & 1.2 & -3.2 & 5.8 & 5775 \\
\hline Myanmar & 8.1 & 1.8 & 4.5 & 11.2 & -0.5 & 1.5 & -3.1 & 2.3 & 63 \\
\hline New Caledonia & 7.1 & 2.9 & -0.2 & 10.7 & 1.8 & 1.8 & -1.4 & 5.2 & 84 \\
\hline New Zealand & 3.8 & 1.4 & -1.9 & 8.2 & 0.8 & 1 & -2.1 & 4.7 & 3108 \\
\hline Nicaragua & 10.9 & 0.4 & 10.1 & 11.6 & 1.2 & 5 & -3.4 & 15 & 21 \\
\hline Oman & 5.5 & 1.6 & 1.1 & 8.6 & 0.2 & 1.3 & -3 & 3.8 & 84 \\
\hline Pakistan & 4.1 & 2.1 & -1.1 & 8.6 & 1 & 1.6 & -3.2 & 6.1 & 1176 \\
\hline Philippines & 3.4 & 1.9 & -4.1 & 9.3 & 0.7 & 1.5 & -3.9 & 6.4 & 2625 \\
\hline Portugal & 3.3 & 1.5 & -5.5 & 9 & 0.2 & 1.2 & -4.1 & 4.8 & 4158 \\
\hline Republic of Korea & 2.9 & 1.6 & -5.9 & 6.9 & 1.8 & 1.6 & -2.7 & 8.8 & 6930 \\
\hline Russia & 2.9 & 1.8 & -4.4 & 7.9 & 1.3 & 2 & -3.3 & 10.9 & 1947 \\
\hline Saint Kitts and Nevis & 6.3 & 0.9 & 4 & 8.8 & -1.6 & 1 & -4.9 & 0.3 & 105 \\
\hline Saudi Arabia & 3.5 & 2.1 & -3.4 & 8.8 & -0.3 & 1.2 & -4 & 5.1 & 861 \\
\hline Spain & 3.2 & 1.1 & -4.6 & 7 & 1.2 & 1.1 & -2.1 & 6.4 & 7140 \\
\hline Sri Lanka & 5.3 & 1.7 & -0.6 & 9.2 & 0.9 & 1.2 & -3.4 & 4.4 & 819 \\
\hline Thailand & 3.8 & 1.5 & -2.8 & 8.3 & 1.5 & 1.6 & -2.8 & 7.5 & 3318 \\
\hline Trinidad and Tobago & 6.3 & 2.2 & -0.6 & 9.4 & 0.2 & 1.1 & -3.3 & 2.8 & 189 \\
\hline United Kingdom & 3.2 & 0.9 & -5.5 & 6.3 & 2.4 & 1.4 & -2.3 & 7.7 & 10059 \\
\hline Venezuela & 3.6 & 2.1 & -4.7 & 9.3 & 0.7 & 1.7 & -3.4 & 7.3 & 1281 \\
\hline Vietnam & 7.3 & 1.9 & 0.7 & 10 & 0.9 & 1.4 & -2.4 & 5.1 & 147 \\
\hline Zimbabwe & 5.9 & 2.3 & -2.8 & 9.5 & -0.4 & 1.5 & -3.8 & 3.6 & 168 \\
\hline
\end{tabular}

